\title{
Comparison of wheat simulation models under climate change. I. Model calibration and sensitivity analyses
}

\author{
J. Wolf ${ }^{1, *}$, L. G. Evans ${ }^{2}$, M. A. Semenov ${ }^{2}$, H. Eckersten ${ }^{3}$, A. Iglesias ${ }^{4}$ \\ ${ }^{1}$ Dept of Theoretical Production Ecology, Wageningen Agricultural University, PO Box 430, Wageningen 6700 AK, \\ The Netherlands \\ ${ }^{2}$ IACR-Long Ashton Research Station, Dept of Agricultural Sciences, University of Bristol, Bristol BS18 9AF, United Kingdom \\ ${ }^{3}$ Dept of Soil Sciences, Swedish Agricultural University, PO Box 7014, S-75007 Uppsala, Sweden \\ ${ }^{4}$ Dept Sistemas Forestales, CIT-INIA, E-28040 Madrid, Spain
}

\begin{abstract}
A comparison of the performance of 5 wheat models was carried out for 2 sites in Europe with considerably different agroclimatic conditions: Rothamsted, UK, and Seville, Spain. The models were calibrated against field data sets from both sites. For Rothamsted the measured time courses of crop growth, evapo-transpiration and nitrogen uptake were reproduced reasonably well by the different models, except for leaf area index. For Seville, the experimental data set was insufficient for such a detailed comparison and mainly simulated results were compared. The sensitivity of the model results to stepwise changes in individual weather variables was then determined. In the different model runs a temperature rise generally resulted in lower yields, an increase in precipitation and atmospheric $\mathrm{CO}_{2}$ concentration resulted in higher yields, and increased variability of weather variables often resulted in lower yields with increased yield variability.
\end{abstract}

KEY WORDS: Climate change - Climatic variability - Inter-model comparison Sensitivity analysis . Simulation model Wheat

\section{INTRODUCTION}

Differences in modelling approach may lead to significant differences in results from crop growth simulation models. This is an important consideration in the context of climate change research as the tendency in such research has been to apply individual crop models using scenarios constructed from a range of GCMs (general circulation models). This provides a useful assessment of the uncertainty surrounding possible future climates. However, uncertainties arising from different crop modelling approaches also need to be quantified.

Crop models should be able to reproduce experimental results for a range of environmental conditions. Such robust and reliable models are critical for pre-

•E-mail: joost.wolf@staff.tpe.wau.nl dicting the response of agriculture to changing climatic conditions. Recently the performance of 3 wheat models was tested against observed crop data in New Zealand (Porter et al. 1993). In this detailed analysis the time courses of absorbed radiation, total and grain dry matter production and other plant characteristics were compared. This indicated where the models differed from reality or from each other and where the models might be improved.

In the Global Change and Terrestrial Ecosystems (GCTE) Focus 3 Wheat Network, 8 wheat models were run for 2 climate data sets, one from Minnesota, USA, and one from The Netherlands. The wheat models differed greatly in complexity, structure and parameterization conditions (GCTE 1994). Model results appeared to differ to a surprising degree. A detailed growth analysis was not undertaken and field data sets were not used for comparison. This made it difficult to trace the cause of the large differences because of the 
complexity and the many feedbacks in the models. The conclusion from this modelling exercise was that crop growth models are not yet at a stage of development where they can be used for strongly different environmental conditions and that they need at least a calibration of their parameter set before they can be applied with confidence (Goudriaan 1996).

Crop models have been developed for widely varying environmental conditions and for different objectives and, hence, emphasize different parts of the plant/soil/climate system. This leads to completely different models, varying in their description of various processes, input requirements and sensitivities to environmental conditions. Furthermore, the description of processes and the parameters in models are often highly related to their testing conditions and are less universal than expected. Therefore, an elaborate calibration step against detailed field experiments is required to make a comparisnn of model results useful.

With climate change, a mean change in climate variables occurs but changes in their variability might also be found (Rind et al. 1989, Mearns et al. 1990). An increase in climatic variability may strongly affect wheat growth and yield as compared to the effects from a mean change in climate, and may lead to a larger yield variation and thus risk of low yields (Semenov \& Porter 1995). In the sensitivity analyses described in this study, the wheat models have been run for climate data sets with increased climate variability to assess such effects. For more information on changes in climatic variability and their consequences for crop growth and yield, the reader is referred to the related climate change study (Semenov et al. 1996, this issue).

In the present study, a comparison of the performance of 5 wheat models for calibration and sensitivity analyses was carried out for 2 sites in Europe which had considerably different climate conditions. The same models have also been applied to future climates, using climate change scenarios (Semenov et al. 1996). The approach applied was consistent with that of the GCTE Wheat Network but was more extensive to prevent some of the problems mentioned above.

\section{METHODOLOGY}

Five wheat models (AFRCWHEAT2, CERES-Wheat, NWHEAT, SIRIUS and SOILN-Wheat) were evaluated. It is often difficult to explain the results and sensitivities of different models on the basis of differences in model structure, source code and input data, as the models' structure is too complex or unknown and too many feedbacks are involved. Hence, the model comparison is largely based on their results.
To analyse the main differences between the models and the consequences for their use in climate change studies, the following procedure was applied. Firstly the models were calibrated against field data sets -in this way the ability of the models to simulate data observed in the field experiments was examined. Then sensitivity analyses of wheat growth and yield to changes in weather variables were carried out. These analyses used climate data sets for current conditions in which temperature, precipitation and atmospheric $\mathrm{CO}_{2}$ concentration were changed independently in a stepwise manner. The results from these analyses showed the correspondence and difference between the models' sensitivity. For the same climate data sets but with increased variability in rainfall and temperature, the model runs were repeated to illustrate the relative importance of changes in climatic variability compared to changes in mean value. All the analyses were conducted for 2 European sites, Rothamsted (United Kingdom) and Seville (Spain). These 2 sites were considered representative for temperate and Mediterranean climate zones, respectively.

The climate data sets generated for the sensitivity analyses were produced for a time period of $30 \mathrm{yr}$ using the LARS-WG stochastic weather generator (Racsko et al. 1991, Barrow \& Semenov 1995). These current climate data were generated on the basis of an historical weather data set. For model calibration and validation, historical sets of weather data were used.

The following crop characteristics can be produced as output by most of the models and appear to characterize well the sensitivities of, and the differences between, the different models (the abbreviations given will be used in the tables):

- Julian day number (January $1=1$, etc.) of emergence, anthesis and maturity: DE, DA, DM;

- grain yield and total above-ground biomass as dry matter $\left(1000 \mathrm{~kg}\right.$ dry matter ha $\left.{ }^{-1}\right): G R, B_{\text {i }}$

- maximum green leaf area index $\left(\mathrm{m}^{2}\right.$ leaf $\mathrm{m}^{-2}$ soil): LAM;

- cumulative evapo-transpiration from emergence to maturity $(\mathrm{mm}): E T_{\text {; }}$

- water use efficiency, i.e. total above-ground biomass/ cumulative evapo-transpiration (g dry matter $\mathrm{kg}^{-1}$ $\mathrm{H}_{2} \mathrm{O}$ ): WUE;

- cumulative intercepted photosynthetically active radiation (PAR) from emergence to maturity (MJ $\left.\mathrm{m}^{-2}\right): \mathrm{RI}_{\mathrm{i}}$

- radiation use efficiency, i.e. total above-ground biomass/cumulative intercepted PAR (g dry matter $\mathrm{MJ}^{-1}$ PAR): RUE;

- harvest index, i.e. grain yield/total above-ground biomass (kg dry matter $\mathrm{kg}^{-1}$ dry matter): $\mathrm{HI}$;

- amount of nitrogen in total above-ground biomass ( $\mathrm{kg} \mathrm{N} \mathrm{ha-1):} \mathrm{NB;}$ 
- nitrogen use efficiency, i.e. total above-ground biomass / amount of nitrogen in total above-ground biomass (kg dry matter $\mathrm{kg}^{-1} \mathrm{~N}$ ): NUE.

Short descriptions of the 5 wheat models used in these comparisons can be found in the report of this study (Wolf et al. 1995). Further details can be found in the following literature: AFRCWHEAT2 (Porter 1984 1993, Weir et al. 1984); CERES (Ritchie \& Otter 1985 , Godwin et al. 1990); NWHEAT (Groot 1987, 1993); SIRIUS (Jamieson \& Wilson 1988, Jamieson 1989, Jamieson et al. unpubl.); and SOILN (Johnsson et al. 1987, Eckersten \& Jansson 1991, Eckersten et al. 1994).

Briefly, all the models, except for SIRIUS, are based on the same phenological development whereby the different stages are dependent on thermal time which may be modified by the crop's response to daylength and vernalisation. The phenology of NWHEAT and SOILN was in fact originally taken from AFRCWHEAT2. For SIRIUS, phenological development is calculated from mainstem leaf appearance rate and final leaf number (which is itself calculated from responses to daylength and vernalisation). SIRIUS also differs significantly in its calculation of leaf area index (LAI), which is based on a simple thermal time model and is therefore independent of biomass calculations. The models sometimes vary in their complexity of approach to the biomass, evaporation/transpiration or nitrogen calculations. For example, CERES contains a detailed grain model which requires careful calibration for different genotypes.

\section{RESULTS AND DISCUSSION}

\subsection{Model calibration}

The models ability to reproduce observed data was tested for the 2 sites, Rothamsted and Seville. For each site, experimental data sets from 2 years were used. The problem of differences in the models' structure and the initialization and parameterization conditions, resulting in large differences in model results and sensitivities, has been mentioned previously. Attempts were made to overcome this by using the following calibration procedure.

For the Rothamsted site, models were initially run for a potential production situation, assuming no limitations to growth from water or nitrogen availability. Subsequently, models were run for a water-limited situation, where crop growth can be limited by water supply from precipitation and soil storage. For Seville, only data from water-limited experiments were available; consequently the models were only run for the water-limited condition (no limitations to growth from nitrogen availability assumed). Calibration against the first set of experimental data was conducted in 3 steps:

(1) phenological development was calibrated such that modelled dates of emergence, anthesis and maturity were within the experimental error of the observed data;

(2) simulated maximum green leaf area index was made (as much as possible) identical to observed data;

(3) simulated biomass and yield were made (as much as possible) identical to the observed data for both the potential and the water-limited production situations.

Each calibrated model was then run for the second year of experimental data. For the 2 years, the models produced output for every $10 \mathrm{~d}$ from sowing to the end of the growing season. Comparisons were drawn both between model predictions and observed data, and between the different model predictions.

\subsubsection{Rothamsted}

Data. The data from 2 experiments carried out at the IACR-Rothamsted Experimental Station were for the winter wheat variety Avalon. The full set of experiments investigated the interactive effects of water and nitrogen on crop growth. In this analysis, only the results from experiments with large amounts of applied fertilizer- $N$ were used and therefore it was assumed in the models that $N$ supply was not a limiting factor for crop growth. In the first experiment used for calibration (Brimstone experiment 1985/86), sown on 10 October 1985 , the crop was either fully irrigated (+I) or covered by a rain shelter (-I) from 29 April 1986 until maturity. In the second experiment (Stackyard experiment 1984/85), sown on 5 October 1984, the crop was either growing on a soil maintained to within $25 \mathrm{~mm}$ of field capacity by irrigation $(+\mathrm{I})$ or was covered by a rain shelter from 17 April 1985 (-I). Further details about the Brimstone experiments in 1985/86 are given by Weir (1988) and about the Stackyard experiments in 1984/85 by Barraclough et al. (1989). Porter (1993) also gives information about these experiments and tests the ability of AFRCWHEAT2 to simulate observed crop growth.

The values for initial and maximum amounts of available water used in the models were based on data from J. R. Porter (pers. comm.). Historical sets of weather data were used. Mean results for the first year (Brimstone 1985/86) are given in Table 1 and for the second year (Stackyard 1984/85) in Table 2. All results except emergence, anthesis and maximum leaf area index are given for the date of maturity. The observed data are mean results from the experiments and the 
Table 1. Plant characteristics as observed in the Brimstone wheat trials [fully irrigated (+I) or with rain shelter from 29 April (-I)] in 1985/86 at the IACR-Rothamsted Experimental Station and as simulated by the different models. Abbreviations are explained in Section 2

\begin{tabular}{|c|c|c|c|c|c|c|c|c|c|c|c|c|c|}
\hline & $D E$ & DA & DM & GR & $\mathrm{TB}$ & HI & $\mathrm{ET}^{\mathrm{O}}$ & WUE ${ }^{d}$ & RI & RUE & LAM & NB & NUE \\
\hline Observed +I & - & 171 & 218 & 9.30 & 19.22 & 0.48 & 326 & 5.61 & - & - & 6.83 & 257 & 74.8 \\
\hline AFRCWHEAT2 +I & 295 & 170 & 219 & 9.11 & 19.77 & 0.46 & 280 & 6.73 & 723 & 2.73 & 7.42 & 202 & 97.9 \\
\hline CERES +1 & 296 & 171 & 218 & 9.27 & 18.56 & 0.50 & 317 & 5.30 & - & - & 4.87 & 244 & 76.0 \\
\hline NWHEAT +I & 295 & 171 & 218 & 9.80 & 19.56 & 0.50 & 319 & 5.99 & 720 & 2.72 & 4.70 & 267 & 73.2 \\
\hline SIRIUS +1 & 296 & 171 & 210 & 8.17 & 19.28 & 0.42 & 264 & 5.68 & - & $2.2^{\mathrm{b}}$ & 8.50 & - & - \\
\hline SOILN +I & 295 & - & 208 & 9.04 & 18.39 & 0.49 & - & - & 773 & $2.38^{\circ}$ & 6.86 & 221 & 83.2 \\
\hline Observed -I & - & 168 & 218 & 7.51 & 15.70 & 0.48 & 219 & 6.48 & - & - & 6.28 & 196 & 80.1 \\
\hline AFRCWHEAT2 -I & 295 & 170 & 219 & 6.06 & 13.55 & 0.45 & 167 & 7.56 & 545 & 2.49 & 5.98 & 139 & 97.5 \\
\hline CERES -I & 296 & 171 & 218 & 6.42 & 15.67 & 0.41 & 246 & 5.65 & - & - & 4.73 & 232 & 67.6 \\
\hline NWHEAT -I & 295 & 171 & 218 & 6.07 & 15.34 & 0.40 & 220 & 6.79 & 688 & 2.23 & 4.49 & 186 & 82.6 \\
\hline SIRIUS -1 & 296 & 171 & 210 & 7.86 & 19.07 & 0.41 & 251 & 5.90 & - & $2.2^{b}$ & 8.50 & - & - \\
\hline
\end{tabular}

variation in experimental results has not been taken into account.

Calibration: 1985/86 experiment. Rates of phenological development were calibrated well in most models (Table 1). Only SIRIUS and SOILN calculated a date of maturity that was too early. The time course of LAI was simulated quite well by AFRCWHEAT2 and SOILN, but both CERES and NWHEAT underestimated LAl whereas SIRIUS overestimated it (see Fig. 1a).

The simulated values for total above-ground biomass and grain yield were quite close to the observed values in the irrigated trial (Table 1). Only SIRIUS calculated a rather low value for yield and hence harvest index. As can be seen from Fig. 1b, the time course of total biomass in the irrigated trial was simulated well by most models, except that SIRIUS (and CERES to a lesser extent) overestimated growth in spring. In the waterlimited trials (with rain shelter) the reduction in total biomass caused by water shortage was reproduced well by CERES and NWHEAT, but the reduction was overestimated by AFRCWHEAT2 and underestimated by SIRIUS. Such over- or underestimation is not a model characteristic but was caused by the input value for soil water storage. Dry matter production is not affected much by LAI values over 4 and hence the differences between simulated and observed LAl described above had little effect on the prediction of total biomass.

The observed values for harvest index were identical for both the water-limited and the irrigated situation, although crop growth in the water-limited situation was strongly reduced by water stress at the end of the growing season. AFRCWHEAT2 and SIRIUS calculated only a slight reduction in the harvest index, but CERES and NWHEAT calculated much lower values in the water-limited situation.
Observed values for evapo-transpiration were given for the period from Day 110 to maturity (Table 1). In the irrigated situation, simulated results from CERES and NWHEAT were almost identical to the observed data (Fig. 1c), however the AFRCWHEAT2 and SIRIUS predictions were too low at the later stages of crop growth. This resulted in a high water use efficiency in AFRCWHEAT2, but not in SIRIUS. This can be explained from the large amount of biomass at Day 110 in the SIRIUS run (Fig. 1b) which resulted in a relatively small increase in biomass from that day until maturity. In the water-limited runs, estimated soil water supply varied from relatively low in AFRCWHEAT2 to rather high in CERES and SIRIUS, which strongly influenced the water losses by evapo-transpiration. Water use efficiency was higher in the water-limited than in the irrigated situation which was due to lower losses through soil evaporation.

AFRCWHEAT2 and NWHEAT calculated about the same values for intercepted PAR and radiation use efficiency. In the other models lower values for radiation use efficiency were used as an input (Table 1). Water limitation resulted in lower efficiency. Water shortage reduced $L A I$, and thus intercepted PAR, more strongly in AFRCWHEAT2 than in NWHEAT. This resulted in a smaller decrease in efficiency by water shortage in AFRCWHEAT2.

The observed values of nitrogen uptake at maturity and nitrogen use efficiency in the irrigated trial were simulated reasonably well by CERES and NWHEAT (Table 1). AFRCWHEAT2 and SOILN calculated a lower nitrogen uptake at the end of the growth period (Fig. 1d) which was probably due to underestimating the total available amount of nitrogen. CERES overpredicted nitrogen uptake in spring, which may be due 
(a) Leaf area index ' $85 /$ ' 86

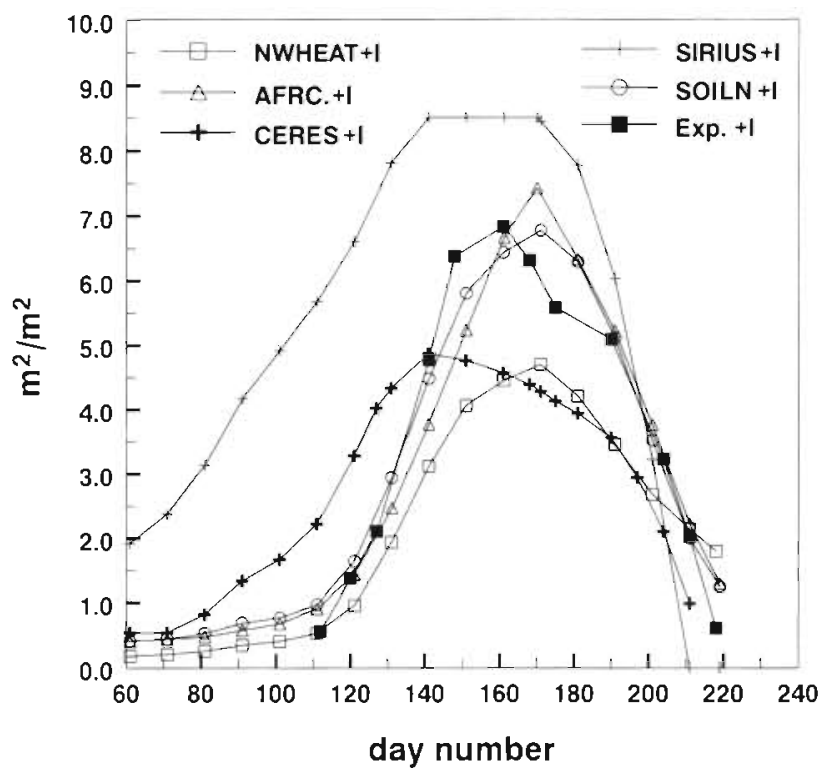

(c) Evapo-transpiration ' $85 /$ '86

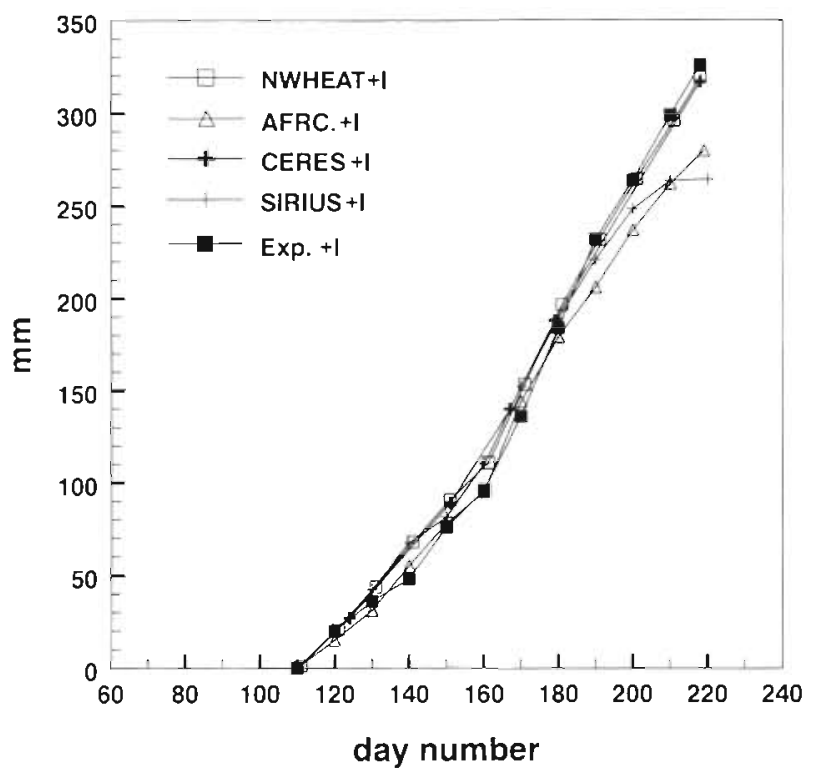

(b) Total biomass ' $85 /$ ' 86

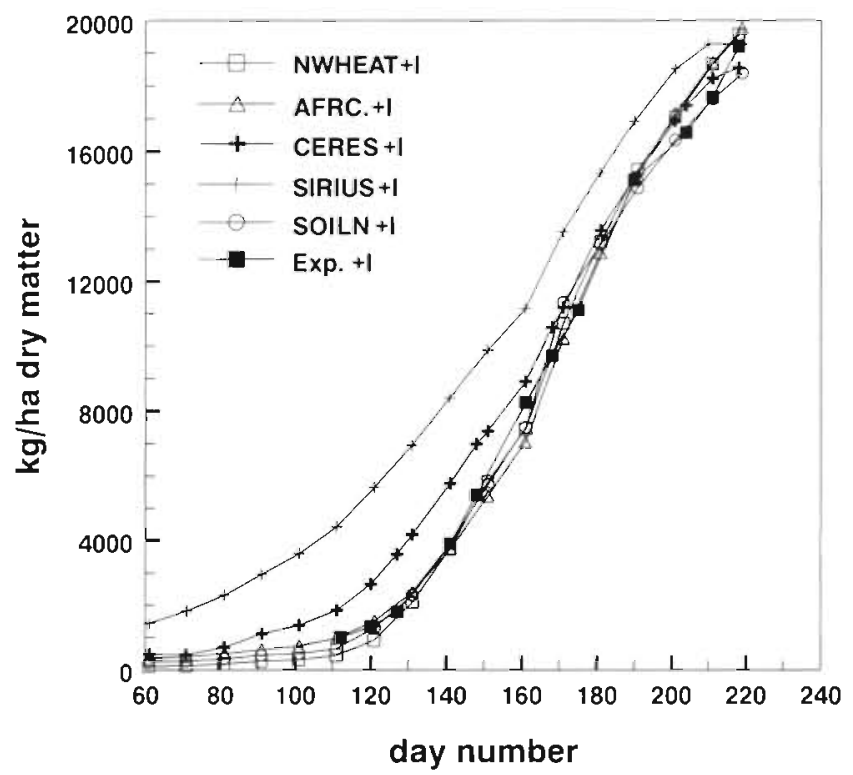

(d) Nitrogen uptake by crop ' $85 / / 86$

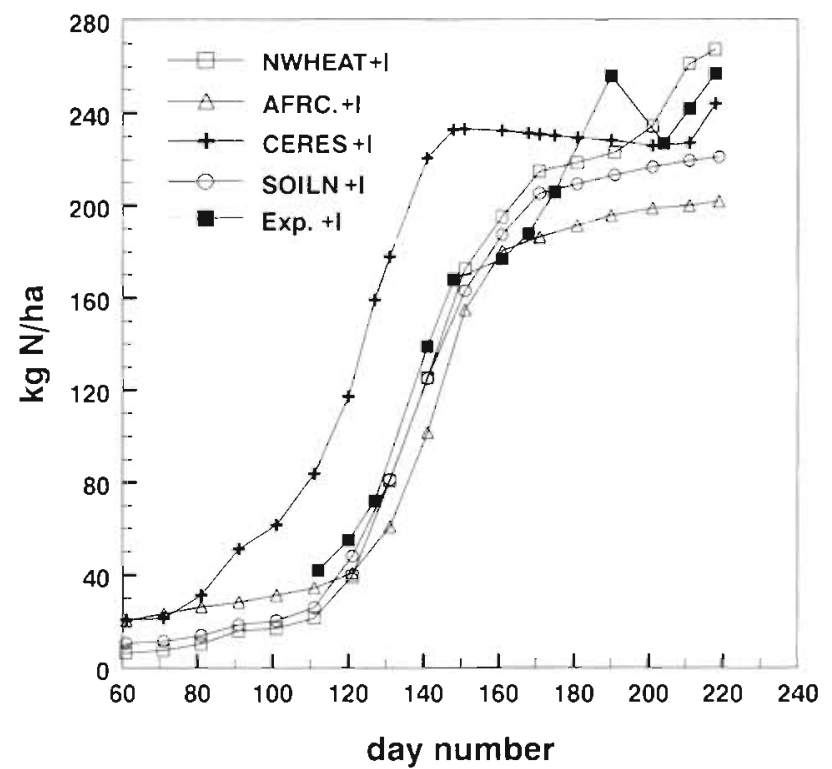

Fig. 1. Time course of (a) leaf area index, (b) total above-ground biomass, (c) cumulative evapo-transpiration and (d) nitrogen uptake for winter wheat as observed in the Brimstone field trials (IACR-Rothamsted Experimental Station, UK) for the treatment with irrigation ( $+\mathrm{I}$ ) and with large amounts of fertilizer-N in the 1985/86 growing season and as simulated with the NWHEAT. AIRCWHEAT2 (AFRC.), CERES, SIRIUS and SOILN models for the potential production situation

to the overestimated growth at this time (see Fig. 1b). In the water-limited experiment, nitrogen uptake was reduced becalise drying of the topsoil reduced the availability of soil and fertilizer nitrogen. AFRCWHEAT2 and NWHEAT simulated this reduced nitrogen uptake.

1984/85 experiment. The simulated and observed dates of anthesis corresponded reasonably well for all the models (Table 2). The dates of maturity calculated by CERES and SIRIUS were reasonably close to the observed date. Those calculated with AFRCWHEAT2 and NWHEAT were about a week too late. This may have been at least partly caused by the high base temperature for post-anthesis phenological development in these madels, which made the length of the grainfilling period sensitive to variation in temperature. 
Table 2. Plant characteristics as observed in the Stackyard wheat trials [fully irrigated (+I) or with rain shelter from 17 April (-I)] in 1984/85 at the IACR-Rothamsted Experimental Station and as simulated by the different models. Abbreviations are explained in Section 2

\begin{tabular}{|c|c|c|c|c|c|c|c|c|c|c|c|c|c|}
\hline & DE & DA & $\mathrm{DM}$ & GR & TB & $\mathrm{HI}$ & $\mathrm{ET}^{\mathrm{a}}$ & WUE $^{a}$ & RI & RUE & LAM & NB & NUE \\
\hline Observed +I & - & 170 & 218 & 8.28 & 17.66 & 0.47 & $268^{b}$ & $5.54^{b}$ & - & - & 6.23 & 203 & 87.0 \\
\hline AFRCWHEAT2 +1 & 290 & 164 & 224 & 10.70 & 21.99 & 0.49 & 290 & 6.87 & 814 & 2.70 & 7.68 & 204 & 107.8 \\
\hline CERES + [ & 288 & 166 & 217 & 10.12 & 20.22 & 0.50 & 291 & 5.58 & - & - & 5.44 & 269 & 75.1 \\
\hline NWHEAT +I & 290 & 169 & 225 & 11.84 & 22.33 & 0.53 & 309 & 6.73 & 849 & 2.63 & 5.70 & 296 & 75.5 \\
\hline SIRIUS +I & 290 & 175 & 220 & 9.05 & 21.05 & 0.43 & 260 & 5.88 & - & $2.2^{c}$ & 8.50 & - & - \\
\hline $\operatorname{SOILN}+I^{d}$ & 289 & - & 221 & 8.35 & 18.81 & 0.44 & - & - & 850 & $2.21^{c}$ & 6.85 & 222 & 84.7 \\
\hline Observed -I & - & 166 & 208 & 6.73 & 15.44 & 0.44 & $200^{b}$ & $6.67^{b}$ & - & - & 5.72 & 161 & 95.9 \\
\hline AFRCWHEAT2 -I & 290 & 164 & 224 & 7.31 & 15.31 & 0.48 & 171 & 7.75 & 622 & 2.46 & 6.33 & 139 & 110.1 \\
\hline CERES - I & 288 & 166 & 217 & 7.80 & 17.68 & 0.44 & 227 & 6.04 & - & - & 5.44 & 255 & 69.3 \\
\hline NWHEAT -I & 290 & 169 & 225 & 5.65 & 15.82 & 0.36 & 197 & 7.24 & 798 & 1.98 & 5.58 & 188 & 84.2 \\
\hline SIRIUS -I & 290 & 175 & 220 & 7.78 & 20.35 & 0.38 & 236 & 6.18 & - & $2.2^{\mathrm{c}}$ & 8.50 & - & - \\
\hline \multicolumn{14}{|c|}{ 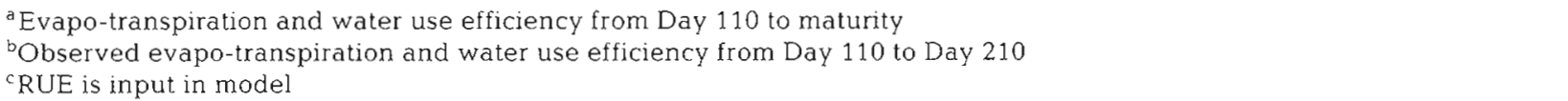 } \\
\hline
\end{tabular}

SOILN required re-calibration of the phenological development to avoid the modelled date of maturity being 1 mo too early. The observed time course of LAl was similar to that from the calibration year 1985/86, however maximum LAI was slightly lower. The predicted time courses of LAI from all the models were also similar to those from the calibration year. NWHEAT and CERES predicted higher values for maximum LAI than those predicted for the calibration year, although these estimates were still lower than the observed value. The estimate of maximum LAI from SOILN corresponded well to the observed value, however the estimates from both AFRCWHEAT2 and SIRIUS were too high.

Simulated total biomass and grain yield were high compared to those observed in the irrigated field trial, except those modelled with SOILN (Table 2). In the water-limited situation, the predicted total biomass and grain yield corresponded quite well to the observed data for AFRCWHEAT2 and NWHEAT, however they were overestimated by both SIRIUS and CERES because the available amount of soil water was overestimated. The time course of total biomass was simulated reasonably well by AFRCWHEAT2, NWHEAT and SOILN up to Day 180 when the observed growth curve began to level off (in contrast to the growth in 1985/86). This part of the curve was only simulated well by SOILN. As for the calibration year, the growth in spring was strongly overestimated by SIRIUS and moderately overestimated by CERES.

In this experiment, water shortage resulted in a slightly lower harvest index (in contrast to the 1985/86 experiment where there was no change). The models responded in the same way as for the calibration year, with AFRCWHEAT2 and SIRIUS calculating slightly lower values and CERES and NWHEAT much lower values in the water-limited situation.

The observed values for evapo-transpiration cover the period from Day 110 to Day 210, however the simulated values cover a period 7 to $15 \mathrm{~d}$ longer (Table 2). Taking this into account, the simulated evapo-transpiration values in the irrigated situation corresponded well to the observed values. The time course of evapotranspiration was simulated fairly accurately by all models, despite the differences between observed and simulated LAI. In the water-limited situation, evapotranspiration was determined by the soil water supply which was, as before, underestimated in AFRCWHEAT2 and overestimated in CERES and SIRIUS. Again, water use efficiency was higher in the waterlimited situation because water losses by soil evaporation were lower.

Estimates of radiation use efficiency from AFRCWHEAT2, NWHEAT and SOILN were close to the efficiencies from the calibration year. As seen previously, water shortage reduced LAI, and thus intercepted PAR, more strongly in AFRCWHEAT2 than in NWHEAT, leading to a smaller decrease in radiation use efficiency in AFRCWHEAT2.

Total nitrogen uptake in the irrigated experiment was simulated well by AFRCWHEAT2 and SOILN (Table 2). The other models overestimated uptake after Day 150, when the rate of nitrogen uptake in the field trial was strongly restricted because of depletion of the 
soil supply. This resulted in reduced total biomass and a relatively high nitrogen use efficiency. This nitrogen limitation may also have reduced the duration of the grain-filling period in the experiment. As before, CERES over-predicted nitrogen uptake in spring. In the water-limited experiment nitrogen supply was reduced by drying of the topsoil, which resulted in a lower value for observed nitrogen uptake and an even higher nitrogen use efficiency. As for the calibration year, AFRCWHEAT2 and NWHEAT predicted reduced nitrogen uptake for the water-limited situation.

\subsubsection{Seville}

Data. Wheat variety trials were carried out at Tomejil in the vicinity of Seville. The varieties were grown on a heavy clay soil (vertisol). A large amount of fertilizer was applied but no irrigation water. The first experiment, used for calibration, was carried out during the 1988/89 growing season (RAEA 1989) and the crop was sown on 7 December 1988. The second experiment was carried out in 1990/91 (RAEA 1991) and the crop was sown on 29 November 1990. For each variety grain yield and anthesis date were given, of which the average of the 3 highest yields and their anthesis dates were used for comparison with the simulated yields and anthesis. The date of harvest, not maturity, was also available for each variety. Date of emergence was the same for all varieties. Other information on the time course of biomass, water use, nitrogen use and LAI during the growth period was not available. Therefore, such results from the model runs can only be compared between models. No results from SOILN were available.

The initial and maximum amounts of available water used in the models were based on data from A. Iglesias and historical sets of weather data were used. The initial amounts of available water in CERES and NWHEAT may have been overestimated as they were set to field capacity at sowing. As large amounts of nitrogen fertilizer were applied in the variety trials, it was assumed in the simulations that nitrogen supply was not limiting for crop growth and nitrogen uptake. All analyses refer to the water-limited situation. Mean results for the first year (1988/89) are given in Table 3 and for the second year (1990/91) in Table 4. All results except emergence, anthesis and maximum LAI are given for the date of maturity.

Calibration: $1988 / 89$ experiment. The simulated dates of emergence and anthesis corresponded well to observed dates (Table 3). The date of maturity was not available from the variety trials. AFRCWHEAT2 and SIRIUS predicted a later date of maturity than CERES and NWHEAT. The highest values for maximum LAI were calculated with AFRCWHEAT2 and SIRIUS. These results for LAI resemble the results from the Rothamsted analyses. An observed value for maximum LAI was not available. The time courses of LAI in the various models were also similar to those from the Rothamsted analyses. This indicates that the time course of LAI can generally be considered a model characteristic that may be influenced to some degree by environmental conditions.

The highest value for total biomass was calculated with NWHEAT and the lowest with AFRCWHEAT2. The predicted yield from CERES corresponded most closely to the observed grain yield, the AFRCWHEAT2 and SIRIUS estimates were slightly too low and the NWHEAT result was too high. These differences may be at least partly due to the initial amount of available water being higher in NWHEAT and CERES compared to AFRCWHEAT2 and SIRIUS. It should also be taken into account that yield losses in variety trials often occur due to diseases during ripening and sub-optimum crop management, and these factors are not incorporated in the wheat models.

Observed values for water losses by evapo-transpiration were not available. CERES and SIRIUS, and NWHEAT to a lesser extent, predicted relatively high evapo-transpiration compared to AFRCWHEAT2. This was probably because AFRCWHEAT2 used a much

Table 3. Plant characteristics as observed in the wheat variety trials in 1988/89 at Tomejil near Seville [water-limited production (-I) onlyl and as simulated by the different models. Abbreviations are explained in Section 2

\begin{tabular}{|c|c|c|c|c|c|c|c|c|c|c|c|c|c|}
\hline & $\mathrm{DE}$ & DA & DM & GR & $\mathrm{TB}$ & $\mathrm{HI}$ & $\mathrm{ET}^{\mathrm{a}}$ & WUE ${ }^{d}$ & RI & RUE & LAM & NB & NUE \\
\hline Observed -I & 359 & 105 & - & $6.27^{b}$ & - & - & - & - & - & - & - & - & - \\
\hline AFRCWHEAT2 -I & 358 & 107 & 151 & 5.49 & 12.16 & 0.45 & 181 & 6.72 & 527 & 2.31 & 7.52 & 221.0 & 55.0 \\
\hline CERES -I & 358 & 107 & 145 & 5.99 & 16.09 & 0.37 & 355 & 4.53 & - & - & 5.59 & 241.7 & 66.6 \\
\hline NWHEAT - I & 358 & 105 & 145 & 7.57 & 18.15 & 0.42 & 304 & 5.98 & 745 & 2.44 & 5.26 & 276.9 & 65.6 \\
\hline SIRIUS - [ & 358 & 106 & 149 & 5.60 & 14.71 & 0.38 & 358 & 4.10 & - & $2.2^{c}$ & 8.50 & - & - \\
\hline
\end{tabular}


Table 4. Plant characteristics as observed in the wheat variety trials in 1990/91 at Tomejil near Seville [water-limited production (-1) onlyl and as simulated by the different models. Abbreviations are explained in Section 2

\begin{tabular}{|c|c|c|c|c|c|c|c|c|c|c|c|c|c|}
\hline & $\mathrm{DE}$ & DA & DM & GR & ТВ & $\mathrm{HI}$ & $E T^{a}$ & WUE & RI & RUE & LAM & NB & NUE \\
\hline Observed -[ & 348 & 104 & - & $6.06^{\mathrm{b}}$ & - & - & - & - & - & - & - & - & - \\
\hline AFRCWHEAT2 -I & 347 & 108 & 156 & 5.49 & 14.36 & 0.38 & 195 & 7.38 & 644 & 2.23 & 7.86 & 255.0 & 56.3 \\
\hline CERES - I & 347 & 110 & 150 & 6.77 & 17.18 & 0.39 & 382 & 4.50 & - & - & 5.57 & 233.8 & 73.5 \\
\hline NWHEAT -I & 349 & 109 & 152 & 8.52 & 19.21 & 0.44 & 296 & 6.50 & 818 & 2.35 & 5.03 & 282.5 & 68.0 \\
\hline SIRIUS - I & 349 & 111 & 155 & 6.18 & 17.06 & 0.36 & 394 & 4.33 & - & $2.2^{c}$ & 8.50 & - & - \\
\hline
\end{tabular}

lower estimate for soil water supply. Thus the water use efficiency varied from a relatively high value for AFRCWHEAT2 etc. to low values for CERES and SIRIUS.

As for the Rothamsted analyses (water-limited situation), the estimate of cumulative intercepted PAR from AFRCWHEAT2 was much lower than from NWHEAT. This might explain the low values for total biomass and evapo-transpiration from AFRCWHEAT2.

Calculated values for nitrogen uptake differed mainly because of differences in total biomass (highest for NWHEAT and lowest for AFRCWHEAT2). The initial rate of nitrogen uptake in CERES was high, which was partly caused by the early start of crop growth and is partly a model characteristic since this trend was also apparent in the Rothamsted analyses. CERES and NWHEAT calculated the same nitrogen use efficiency. Water supply was strongly limiting in AFRCWHEAT2 which resulted in a lower value for nitrogen use efficiency.

1990/91 experiment. All models calculated dates of emergence that corresponded well to observed emergence (Table 4). The modelled dates of anthesis were all slightly later than the observed date. SIRIUS and AFRCWHEAT2 calculated slightly later dates of maturity than the other 2 models. As for the calibration year, the highest values for maximum LAI were calculated by SIRIUS and AFRCWHEAT2. The time courses of LAI were very similar to those from the 1988/89 Seville experiment and the Rothamsted analyses.

The time courses of total biomass from all models were also very similar to those for the calibration year. As before in the Seville analyses, the highest grain yield was calculated by NWHEAT, while the other models calculated lower grain yields that corresponded well with the average grain yield from the variety trials.

As for the 1988/89 experment, the highest evapo-transpiration was predicted by CERES and SIRIUS, the lowest by AFRCWHEAT2. For SIRIUS and CERES, evapotranspiration during the initial part of the growing season was relatively high, caused by the high values for
LAI. Again, water use efficiency was relatively high for AFRCWHEAT2 and low for CERES and SIRIUS.

Nitrogen uptake was similar to that simulated for the first year, except that AFRCWHEAT2 predicted a higher rate of uptake over the whole growing season which was probably due to the water supply being less strongly limiting. NWHEAT again calculated the highest nitrogen uptake because of the high total biomass.

\subsection{Model sensitivity to systematic changes in climate}

\subsubsection{Data}

A baseline climate data set for current conditions was generated for a time period of $30 \mathrm{yr}$. Weather variables in the baseline data set were adjusted independently, in a stepwise manner, in order to gauge the sensitivity of model results to changing values of each variable. The following output variables from crop growth simulations were compared: grain yield, cumulative evapo-transpiration (from sowing to maturity) and CV (coefficient of variation) of grain yield. For each output variable, the values given are the mean of $30 \mathrm{yr}$ of crop growth simulations. CERES and NWHEAT were used for both potential and waterlimited production situations, SOILN for the potential production situation, and AFRCWHEAT2 and SIRIUS for the water-limited production situation.

The sensitivity of model results to the following variables was analysed: total precipitation, which affects duration and degree of water stress and thus crop growth and transpiration; atmospheric $\mathrm{CO}_{2}$ concentration, which affects both $\mathrm{CO}_{2}$ assimilation rate and crop transpiration rate, and hence crop growth; temperature, which mainly affects the rate of phenological development and thus the lengths of the vegetative and grain-filling periods. These analyses were carried out for the 2 sites, Rothamsted and Seville, and for both mean changes in climatic variables and changes in climatic variability. 
(a) Grain yield

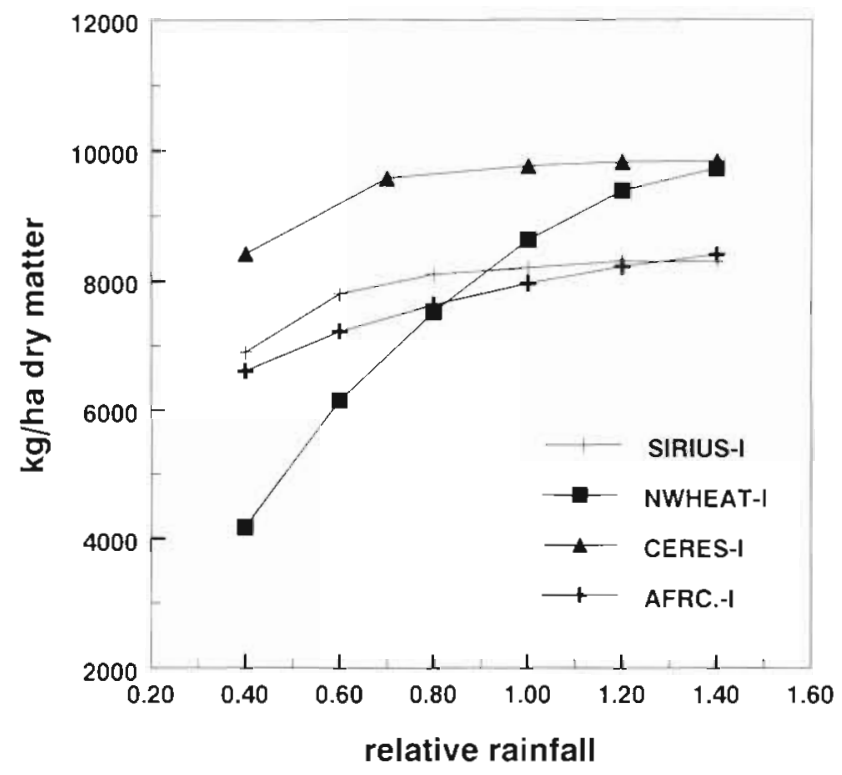

Fig. 2. Sensitivity of (a) grain yield, (b) cumulative evapo-transpiration and (c) CV of grain yield to precipitation for winter wheat in Rothamsted, UK, as simulated with the SIRIUS, NWHEAT, CERES and AFRCWHEAT2 (AFRC.) models for the water-limited (-I) production situation. Results were established for 30 yr of generated weather data for the baseline climate where precipitation values were changed as indicated

\subsubsection{Rothamsted}

Mean changes in climate. For winter wheat in Rothamsted, higher rainfall resulted in increased grain yield and evapo-transpiration in the absence of irrigation (Fig. 2). These increases were larger in NWHEAT than in the other models. AFRCWHEAT2 calculated relatively low values of evapo-transpiration. The CV of grain yield changed very little with increasing amounts of precipitation in AFRCWHEAT2, slightly decreased in CERES and SIRIUS and strongly decreased from a relatively high value in NWHEAT. These results illustrate the effect of reducing the risk of

\section{(b) Evapo-transpiration}

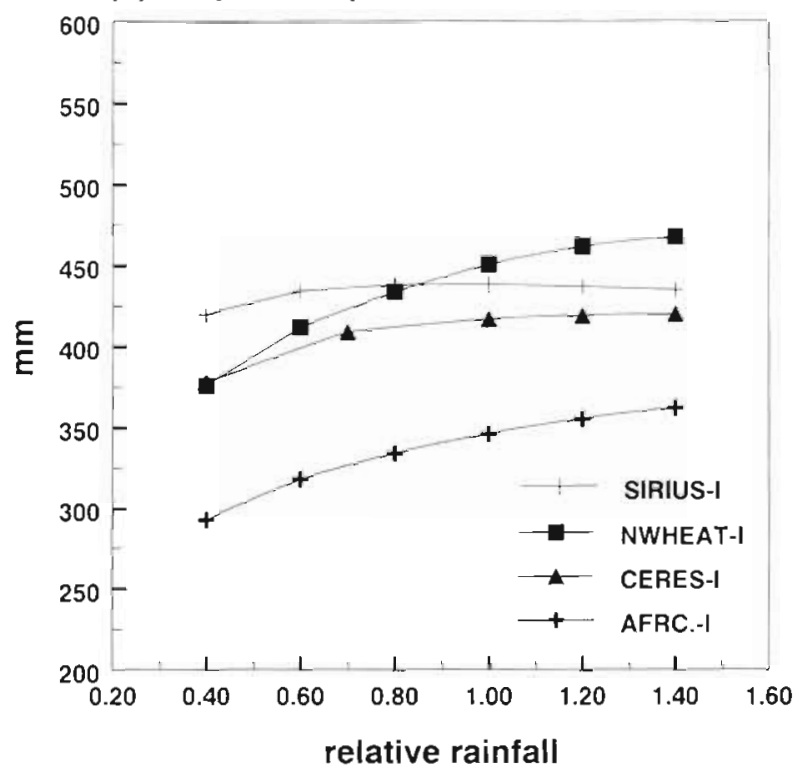

(c) CV of grain yield

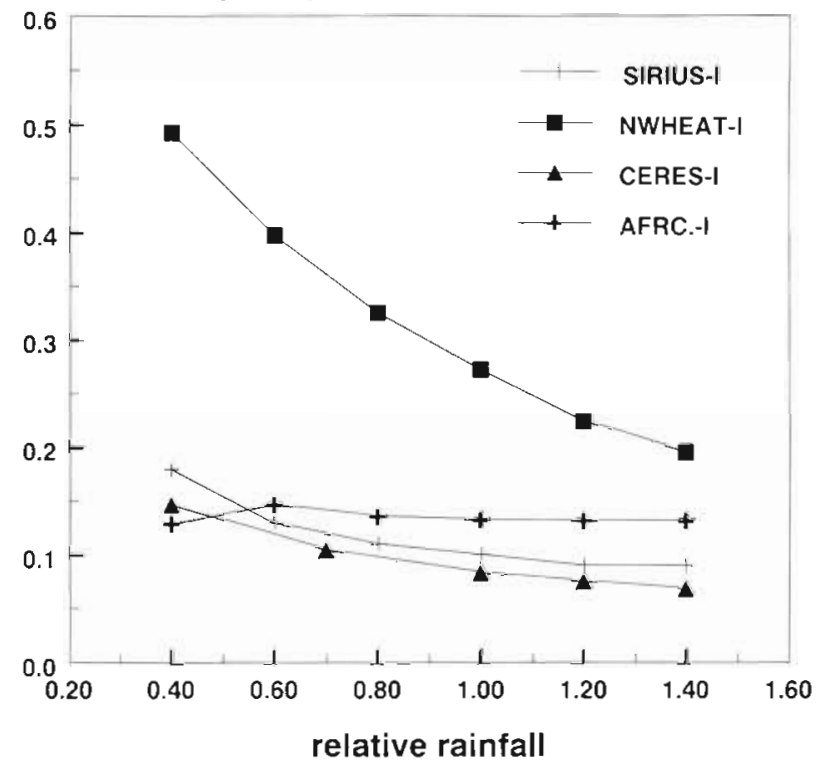

water shortage on yield uncertainty, particularly for NWHEAT, indicating a more limited soil water supply in this model.

Increasing concentrations of atmospheric $\mathrm{CO}_{2}$ resulted in very similar increases in grain yield in all models (Fig. 3). The $\mathrm{CO}_{2}$ effect on yield was linear in AFRCWHEAT2, CERES and SIRIUS, but curvilinear in NWHEAT. This response in NWHEAT is due to its crop growth routine: at low temperatures, the $\mathrm{CO}_{2}$ effect is absent and this interaction limits the $\mathrm{CO}_{2}$ effect strongest at the highest $\mathrm{CO}_{2}$ concentration; also, $\mathrm{CO}_{2}$ concentration affects the $\mathrm{CO}_{2}$ assimilation-light response curve in a non-linear way. CERES showed no 


\section{(a) Grain yield}

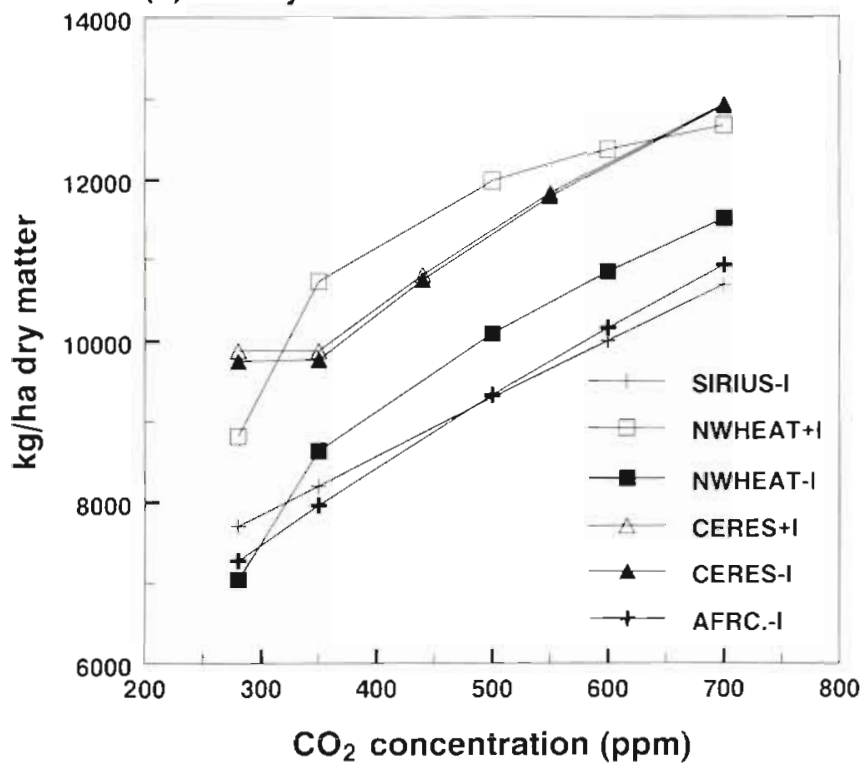

(b) Evapo-transpiration

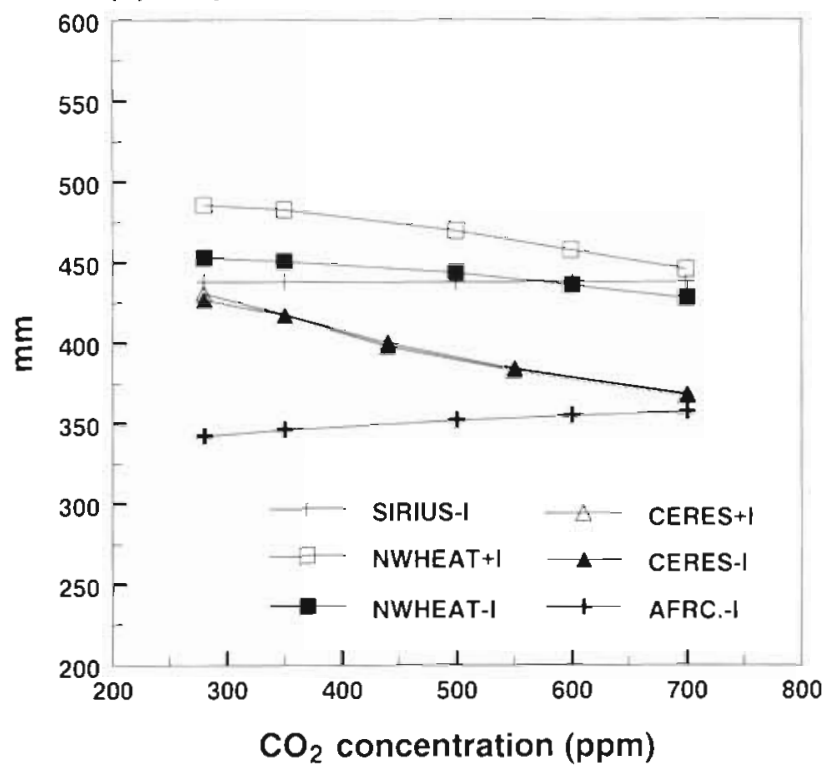

(c) CV of grain yield

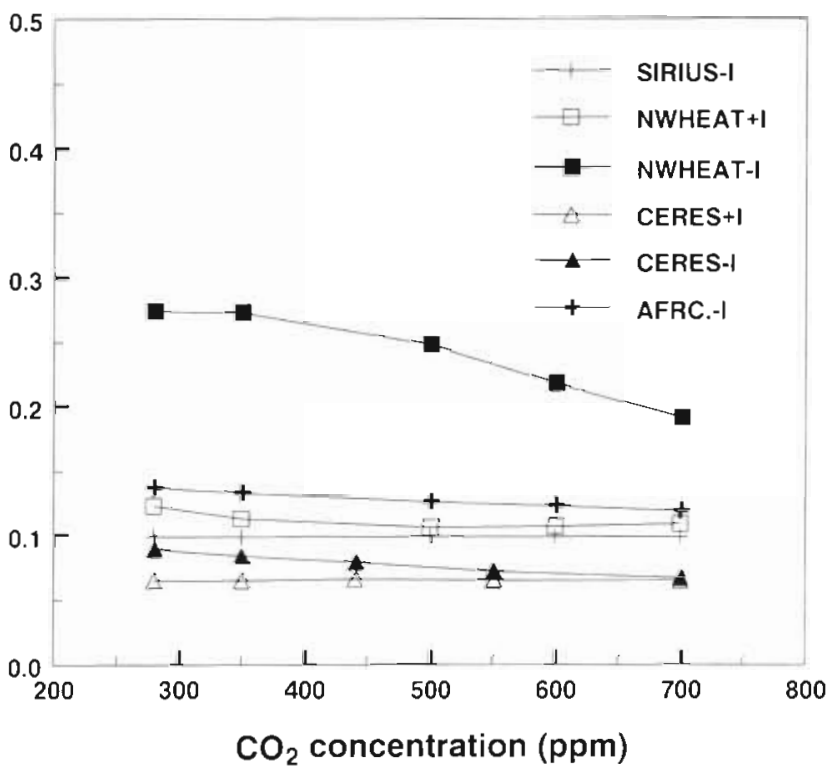

decrease in the duration of the grain filling period. Grain yields in NWHEAT and AFRCWHEAT2 were strongly affected by low temperatures $\left(-4^{\circ} \mathrm{C}\right.$ change): NWHEAT predicted a low yield, because $\mathrm{CO}_{2}$ assimilation rate and hence growth rate are lower at low temperatures; AFRCWHEAT2 predicted no yield, due to the date of anthesis becoming so late that the crop did not reach maturity. Water losses by evapo-transpiration decreased with rising temperatures in CERES and NWHEAT, mainly due to the advancement of the date of maturity. In contrast, SIRIUS predicted increases in evapo-transpiration with rising temperatures. AFRCWHEAT2 predicted a relatively low evapo-transpiradue to advancement of the date of maturity and a 
(a) Grain yield

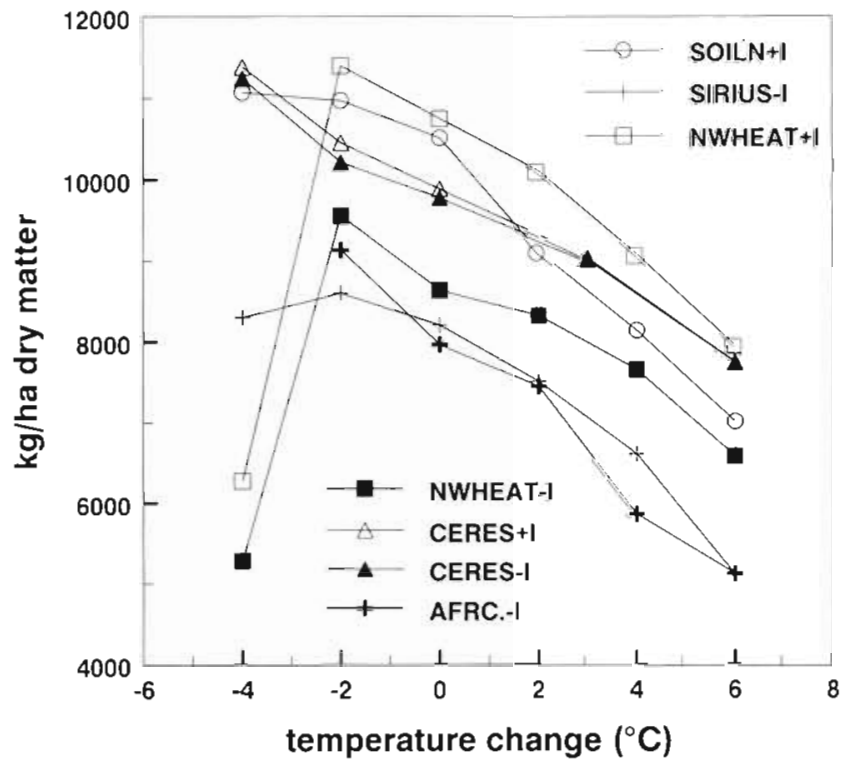

Fig. 4. Sensitivity of (a) grain yield, (b) cumulative evapotranspiration and (c) CV of grain yield to changes in mean temperature for winter wheat in Rothamsted, UK, as simulated with the SOILN, SIRIUS, NWHEAT, CERES and AFRCWHEAT2 (AFRC.) models for the potential (+I) and waterlimited $(-\mathrm{I})$ production situations. Results were established for $30 \mathrm{yr}$ of generated weather data for the baseline climate where temperature values were changed by the amounts indicated

tion that was largely unaffected by temperature change. The predicted evapo-transpiration in CERES was higher than that in AFRCWHEAT2, but lower than that in SIRIUS and NWHEAT. The CV of grain yield was largely unaffected by temperature change, except at $-4^{\circ} \mathrm{C}$ in NWHEAT $(+\mathrm{I})$ and SIRIUS, and +4 and $+6^{\circ} \mathrm{C}$ in AFRCWHEAT2. As before, NWHEAT calculated a higher $\mathrm{CV}$ for the water-limited than for the potential production situation due to increased risk of water shortage.

Increases in climatic variability. Simulations were also conducted for the same climatic data set including changes in climatic variability. The daily variability in

\section{(b) Evapo-transpiration}

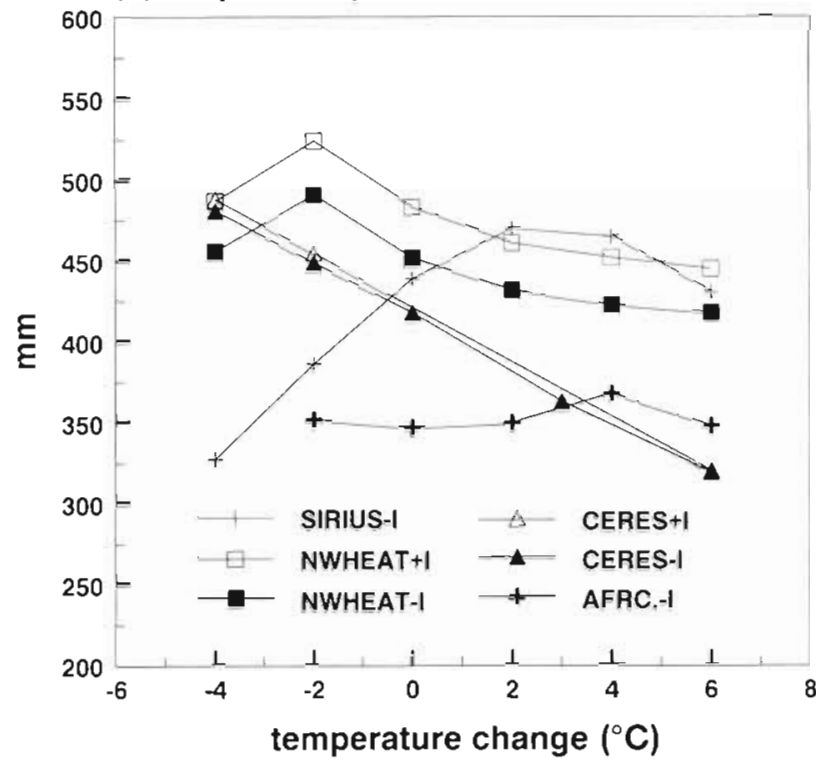

(c) CV of grain yield

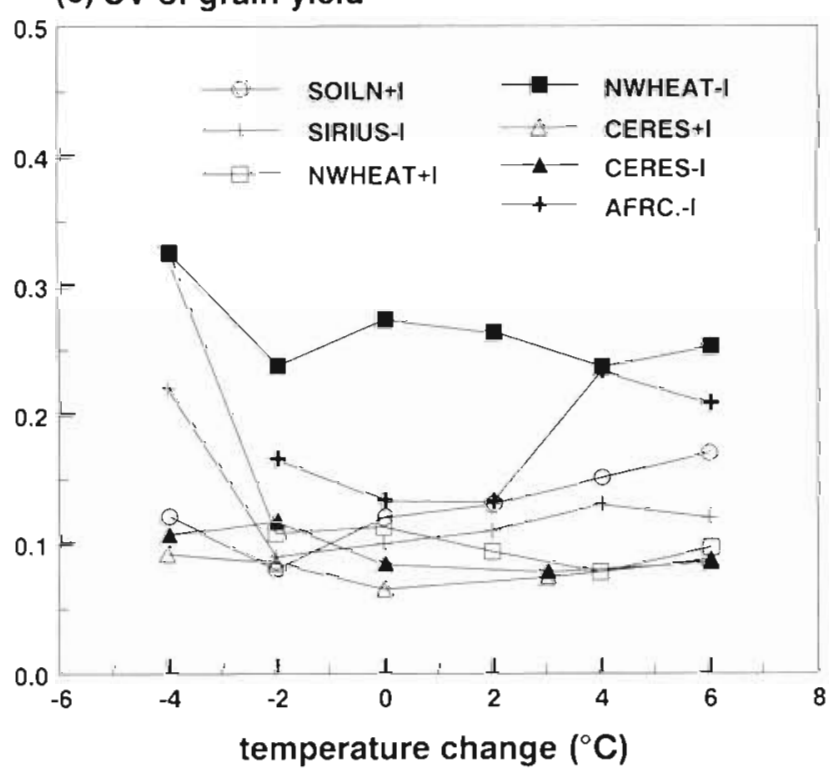

temperature was doubled in combination with mean changes in temperature, comparable to those mentioned above. As before, at higher temperatures the models predicted lower grain yields (Fig. 5). Including the doubled temperature variability reduced the yields in CERES, NWHEAT and SOILN, but did not change those in AFRCWHEAT2 and SIRIUS (see Fig. 4 for comparison). In winter wheat experiments in controlled environment chambers, increased diurnal variation in temperature resulted in a decrease in grain yield but not in total dry matter, probably because of a delayed onset of grain-filling (J. R. Porter pers. comm.). The implication of these experimental data versus the 
(a) Grain yield

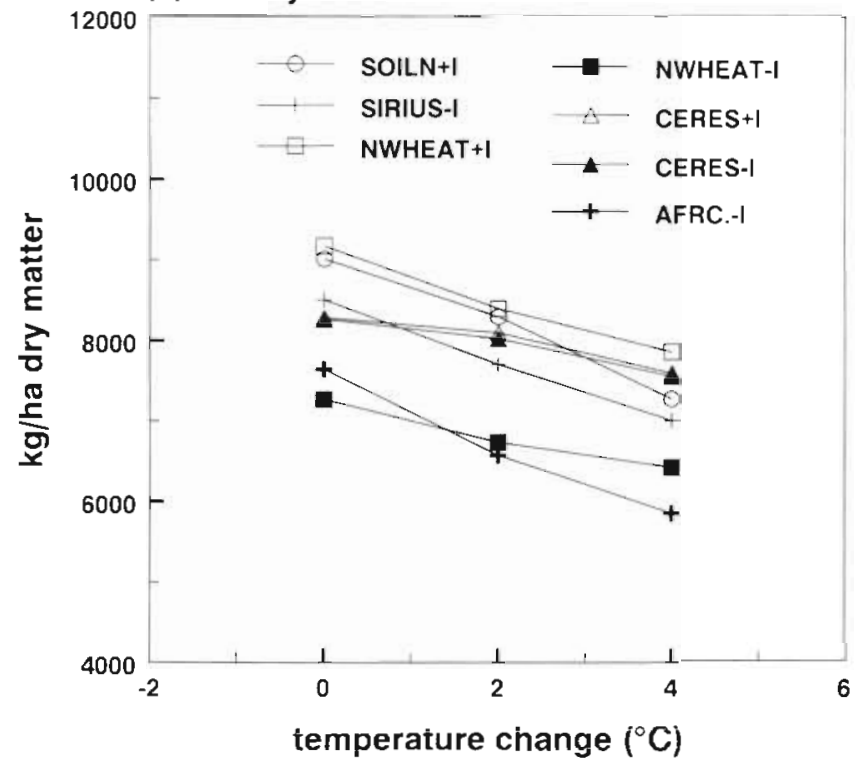

(b) CV of grain yield

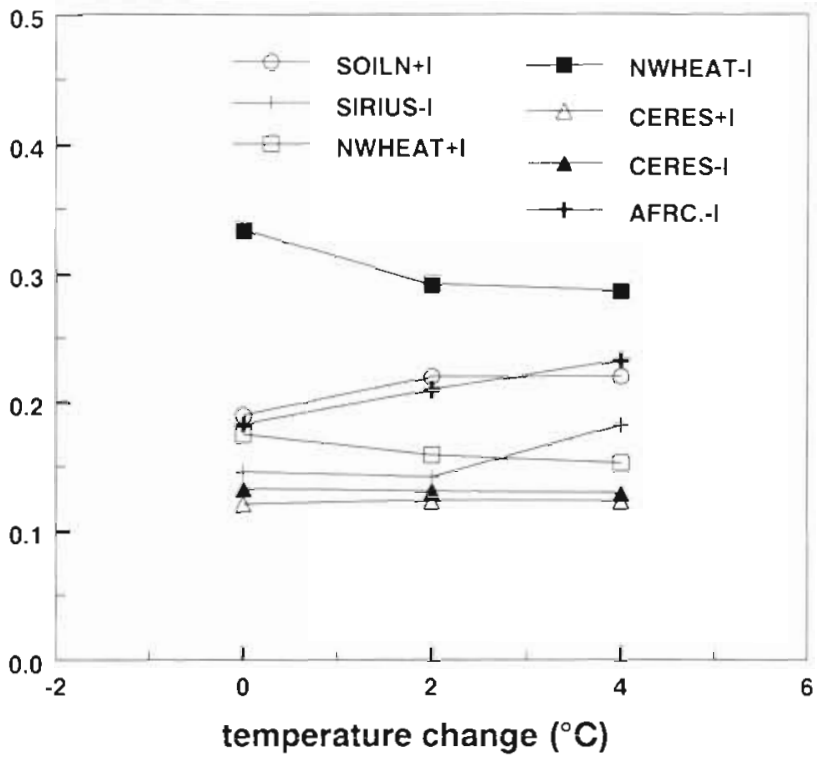

Fig. 5. Sensitivity of (a) grain yield and (b) CV of grain yield to changes in mean temperature and temperature variability for winter wheat in Rothamsted, UK, as simulated with the SOILN, SIRIUS, NWHEAT, CERES and AFRCWHEAT2 (AFRC.) models for the potential (+1) and water-limited (-1) production situations. Results were established for 30 yr of generated weather data for the baseline climate where the temperature variability was doubled and the mean temperature values were changed by the amounts indicated

modelling results is not yet clear and further experimentation is needed. Predicted evapo-transpiration in all models was similar to that from the analyses without doubled temperature variability. The values for CV of grain yield in all models were slightly higher than those in the comparable runs without doubled temperature variability (Fig. 5b)

The effects of rainfall distribution on crop growth and water use were analysed by doubling the length of dry spells in the baseline climate data set. SIRIUS and (a) Grain yield

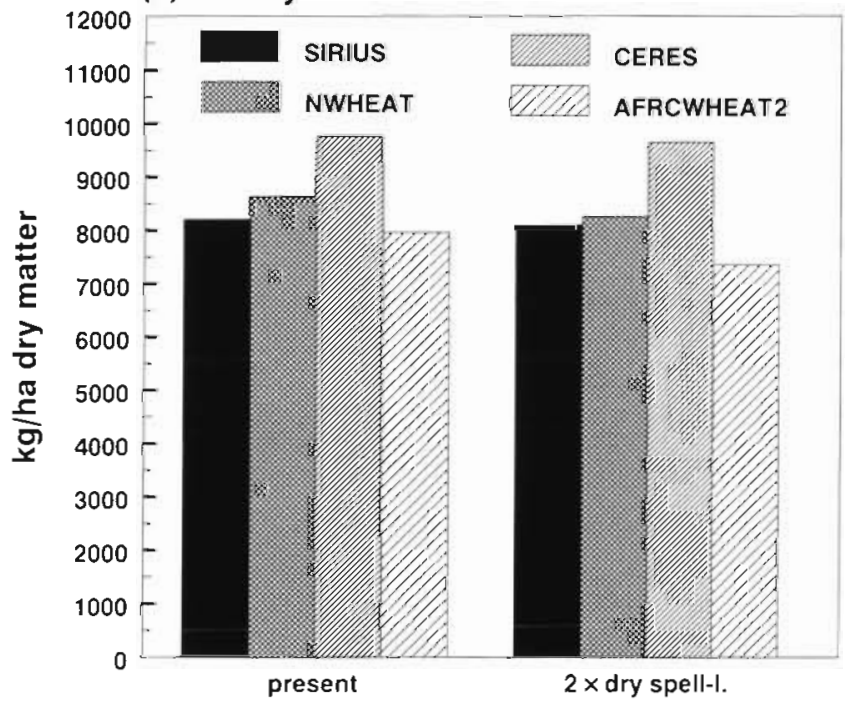

(b) CV of grain yield

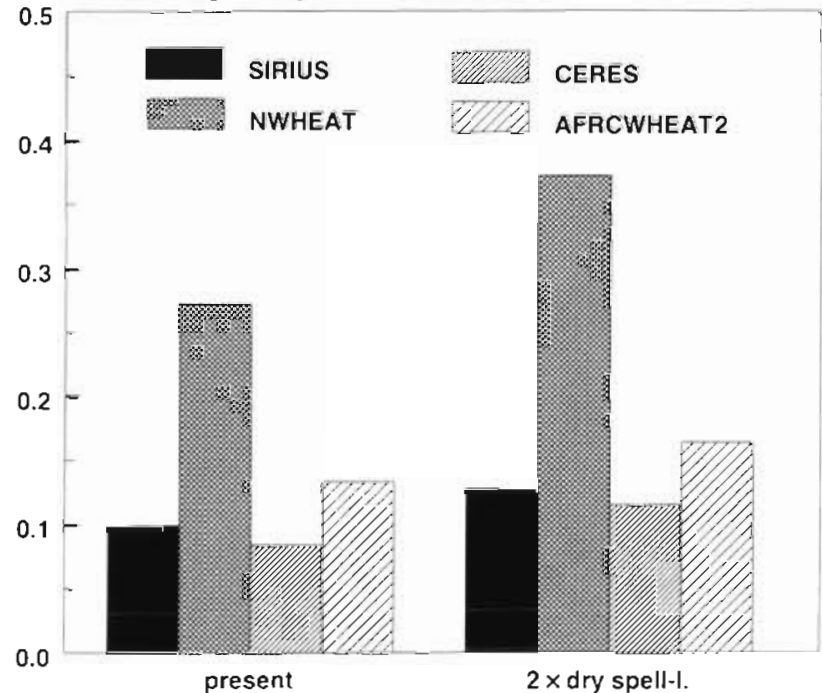

Fig. 6. Sensitivity of (a) grain yield and (b) CV of grain yield to rainfall distribution for winter wheat in Rothamsted, UK, as simulated with the SIRIUS, NWHEAT, CERES and AFRCWHEAT2 models for the water-limited (-I) production situation. Results were established for $30 \mathrm{yr}$ of generated weather data for the baseline climate where the length of dry spells was doubled 
CERES predicted identical values for grain yield and evapo-transpiration with doubled dry spell length. The other models predicted slightly lower values for grain yield and evapo-transpiration in the water-limited situation (Fig. 6). These results indicate that the severity of water shortage did not increase much by doubling the length of dry spells. The CVs of grain yield in AFRCWHEAT2, CERES and SIRIUS were low and increased slightly when the length of the dry spells was doubled. $\mathrm{CV}$ in NWHEAT was much higher and increased more strongly with the doubled dry spell length, indicating that NWHEAT is particularly sensitive to the yieldreducing effect of water shortage.

\section{(a) Grain yield}

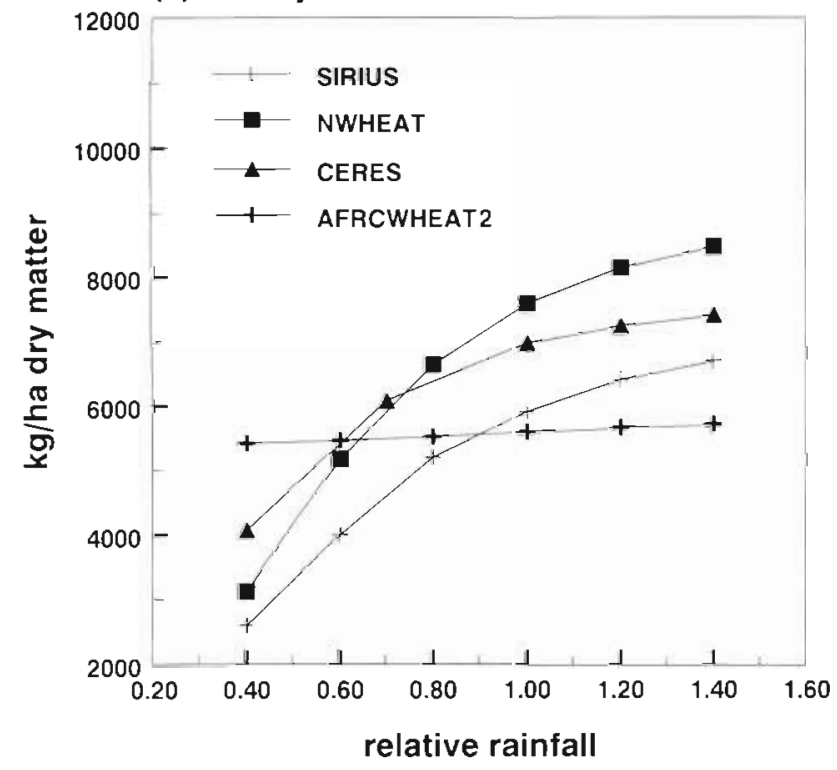

Fig. 7. Sensitivity of (a) grain yield, (b) cumulative evapotranspiration and (c) $\mathrm{CV}$ of grain yield to precipitation for winter wheat in Seville, Spain, as simulated with the SIRIUS, NWHEAT, CERES and AFRCWHEAT2 models for the waterlimited (-I) production situation. Results were established for $30 \mathrm{yr}$ of generated weather data for the baseline climate where precipitation values were changed as indicated

\subsubsection{Seville}

Mean changes in climate. For wheat in Seville, increasing rainfall resulted in higher grain yields in most water-limited situations (Fig 7). The yield increase in NWHEAT was greater than in CERES and SIRIUS. Water supply did not limit crop yield in AFRCWHEAT2. All models predicted an increase in evapotranspiration with increasing precipitation. Evapotranspiration in AFRCWHEAT2 was relatively low. CV of grain yield was constant and relatively low in AFRCWHEAT2, indicating lack of response to water shortage. All other models predicted a rapid decrease in $\mathrm{CV}$

\section{(b) Evapo-transpiration}

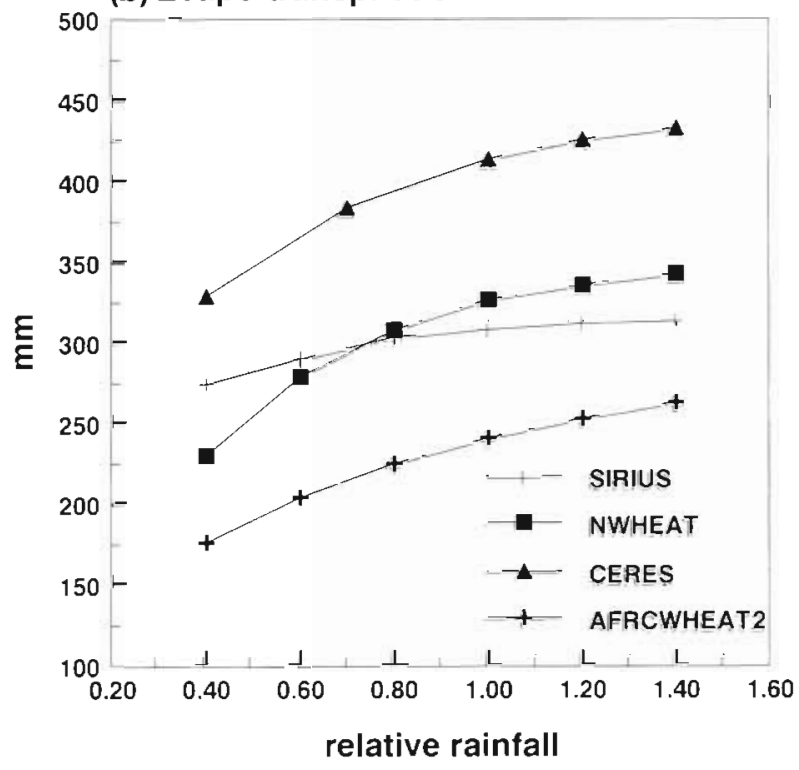

(c) CV of grain yield

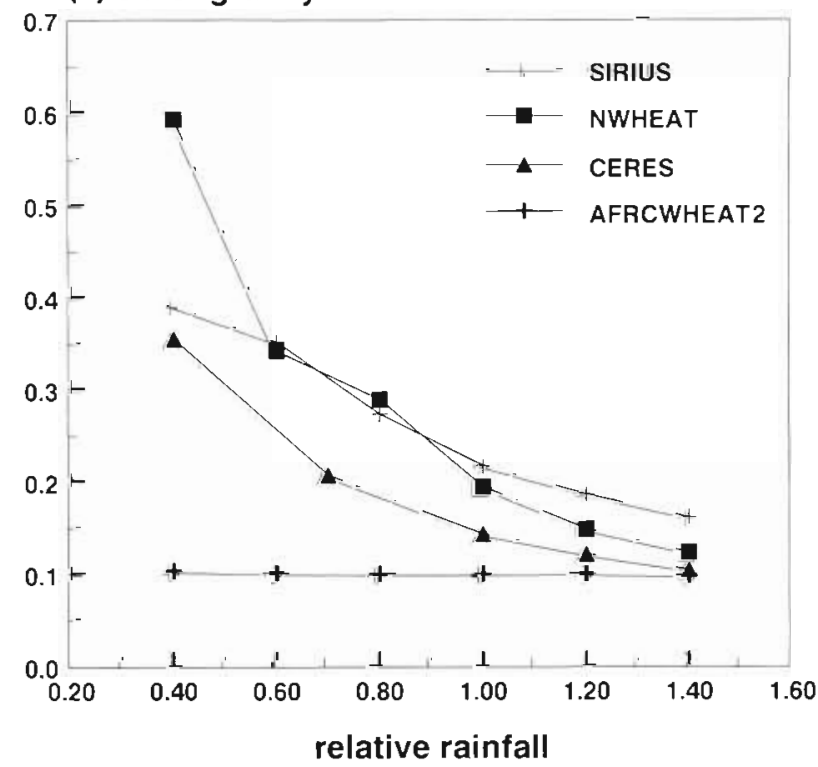


with increasing precipitation. These results resemble the results from the Rothamsted analyses, with the exception that water supply appears to be almost nonlimiting for AFRCWHEAT2

Increasing atmospheric $\mathrm{CO}_{2}$ concentration had the same effect on grain yield predictions as seen for Rothamsted (increasing values with increasing $\mathrm{CO}_{2}$ ). Evapo-transpiration was also very similar, with very little change in AFRCWHEAT2 and SIRIUS and decreasing values in NWHEAT and CERES. CV of grain yield did not change with increasing atmospheric $\mathrm{CO}_{2}$, except in CERES and NWHEAT under water-lim-

(a) Grain yield

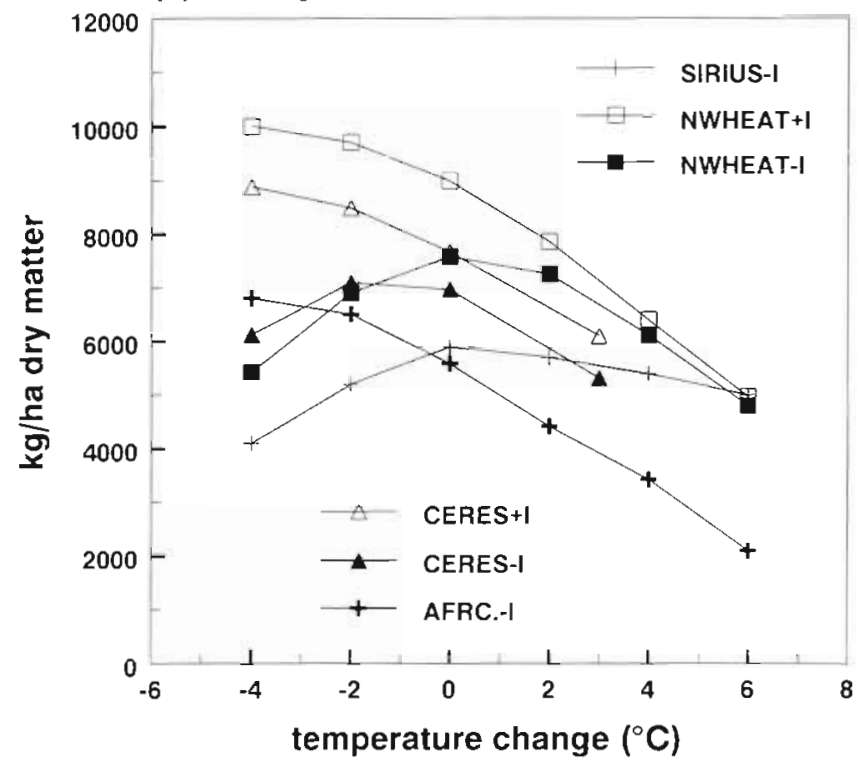

Fig. 8. Sensitivity of (a) grain yield, (b) cumulative evapotranspiration and (c) CV of grain yield to changes in mean temperature for winter wheat in Seville, Spain, as simulated with the SIRIUS, NWHEAT, CERES and AFRCWHEAT2 (AFRC.) models for the potential (+I) and water-limited (-I) production situations. Results were established for $30 \mathrm{yr}$ of generated weather data for the baseline climate where temperature values were changed by the amounts indicated ited conditions where the increases in atmospheric $\mathrm{CO}_{2}$ caused a decrease in evapo-transpiration, and hence in water shortage, which resulted in a decrease in CV.

Warming resulted in a decrease in grain yield in all models (Fig. 8). This was, as for Rothamsted, due to shortening of the grain-filling period. SIRIUS predicted a smaller decrease in grain yield with warming than did the other models. With cooling, SIRIUS, CERES and NWHEAT (water-limited analyses) predicted a decrease in grain yield, in contrast to AFRCWHEAT2 and the potential production analyses

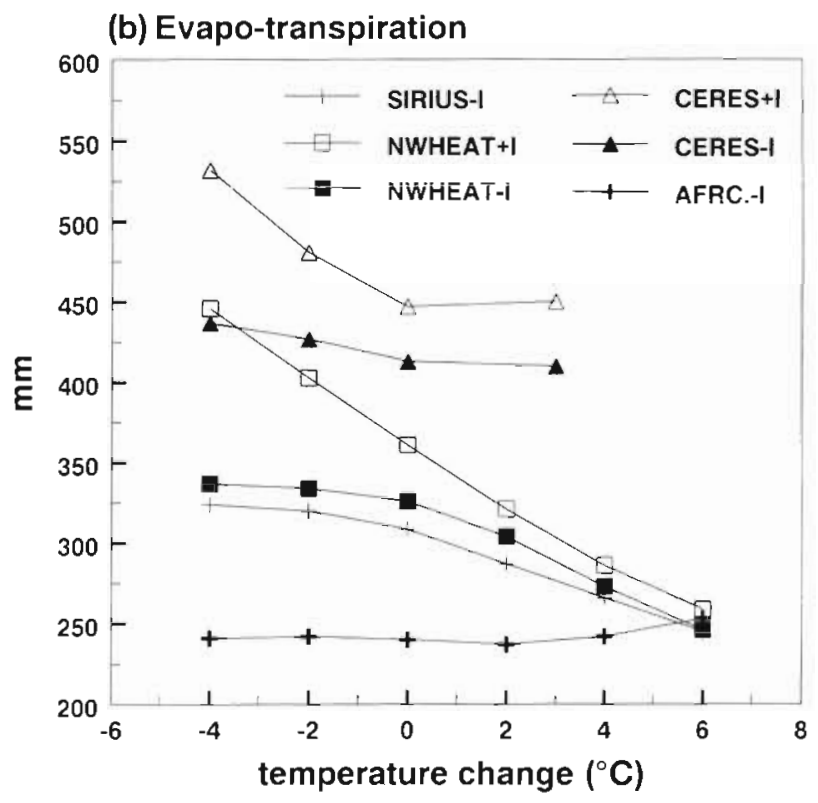

(c) CV of grain yield

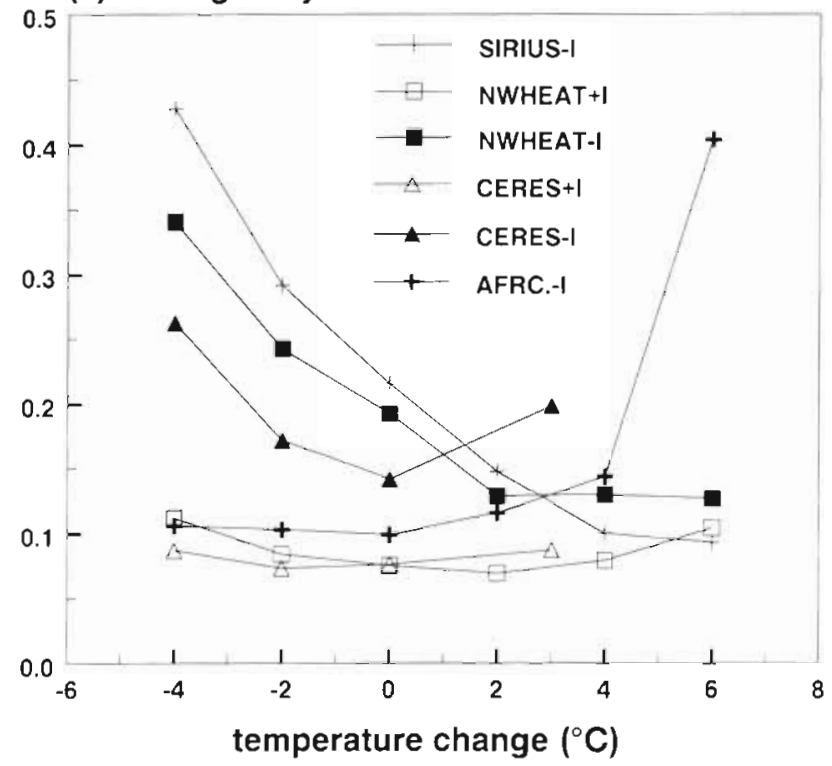


(NWHEAT and CERES). This decrease in yield was due to soil water supply becoming more limiting during the longer period of growth at lower temperatures. Generally, the models predicted decreasing evapo-transpiration with increasing temperature, however AFRCWHEAT2 predicted no change. CERES predicted higher evapo-transpiration than all other models. This was in contrast to the Rothamsted results, where NWHEAT and SIRIUS calculated higher values of evapo-transpiration than CERES. It is unclear whether these differences can be explained by the different methods employed to calculate evapo-transpiration. In the water-limited analyses the decrease in evapo-transpiration with increasing temperature was smaller than in the potential production analyses, which was caused by the increase in water shortage at cooler temperatures. CVs of grain yield were high if water shortage affected crop growth severely (water-limited situations, in particular at lower temperatures). CV of grain yield in AFRCWHEAT2 was generally low, except for $+6^{\circ} \mathrm{C}$ warming where a strong increase in CV accurred.

Increases in climatic variability. As for Rothamsted, simulations were carried out for the same climatic data set including changes in climatic variability. When doubling daily variability in temperature (concurrent with mean changes in temperature), warming generally resulted in a decrease in grain yield (Fig. 9), with the exception of SIRIUS which predicted a fairly con- stant yield. Doubling the temperature variability considerably reduced the yields in AFRCWHEAT2, CERES and NWHEAT (see Fig. 8 for comparison). As in the comparable Rothamsted analyses, it did not affect the yields from SIRIUS. Evapo-transpiration was hardly affected by doubled temperature variability, however CV of grain yield increased slightly to moderately in all analyses (see Fig. 8), a result comparable to that in the Rothamsted analyses. In most models, the rate of $\mathrm{CO}_{2}$ assimilation is reduced at temperatures outside the optimum range. Increased variability in temperature results in more days at sub-optimum tem. peratures and therefore reduced $\mathrm{CO}_{2}$ assimilation, leading to lower average yields and higher CVs.

Doubling the length of the dry spells considerably reduced grain yield predictions in CERES, NWHEAT and SIRIUS under water-limited conditions (Fig. 10). In AFRCWHEAT2 yield did not change but evapo-transpiration decreased strongly. In the other models, evapo-transpiration also decreased with doubled dry spell length as a result of the more limited water supply. CV of grain yield in CERES, NWHEAT and SIRIUS strongly increased with this change in rainfall distribution, however in AFRCWHEAT2 analyses $\mathrm{CV}$ remained low. These results can be explained by the fact that cumulative precipitation was approximately halved when the length of dry spells was doubled. It would appear that soil water supply in AFRCWHEAT2 was large enough to compensate for this effect. (a) Grain yield

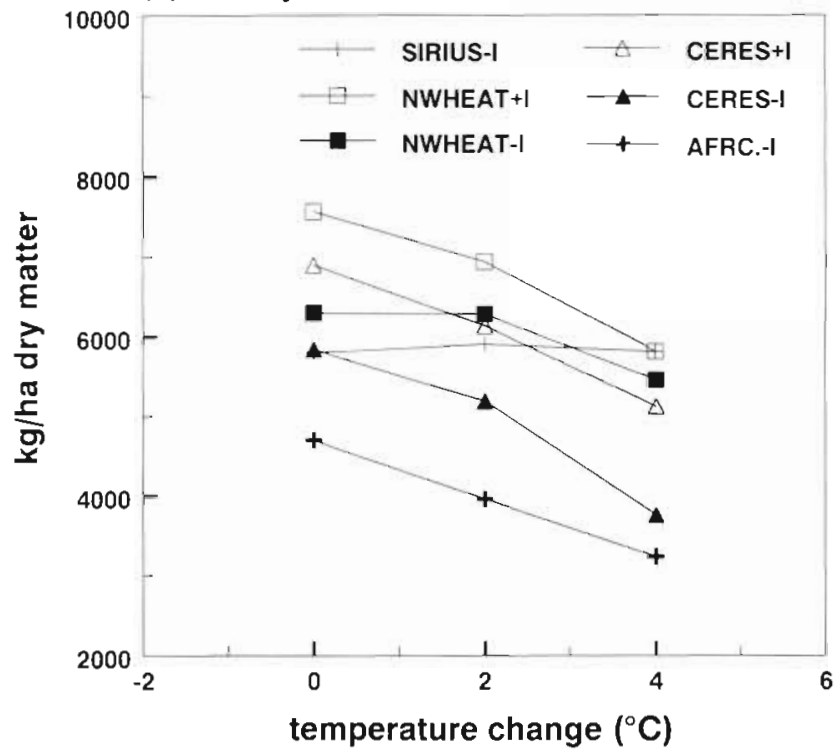

(b) CV of grain yield

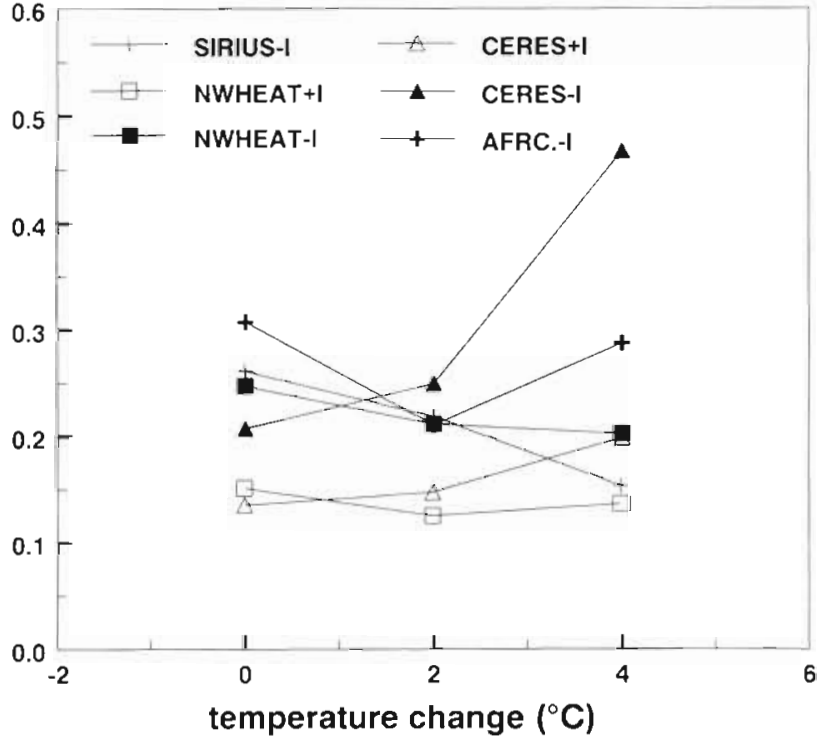

Fig. 9. Sensitivity of (a) grain yield and (b) CV of grain yield to changes in mean temperature and temperature variability for winter wheat in Seville, Spain, as simulated with the SIRIUS, NWHEAT, CERES and AFRCWHEAT2 (AFRC.) models for the potential (+I) and water-limited (-I) production situations. Results were established for $30 \mathrm{yr}$ of generated weather data for the baseline climate where the temperature variability was doubled and the mean temperature values were changed by the amounts indi- 
(a) Grain yield

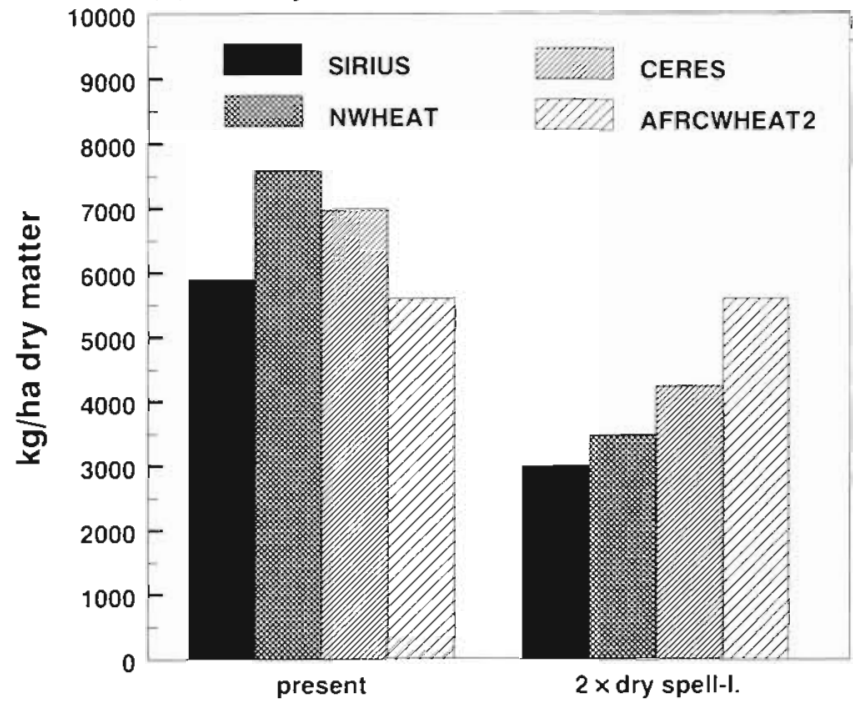

(b) CV of grain yield

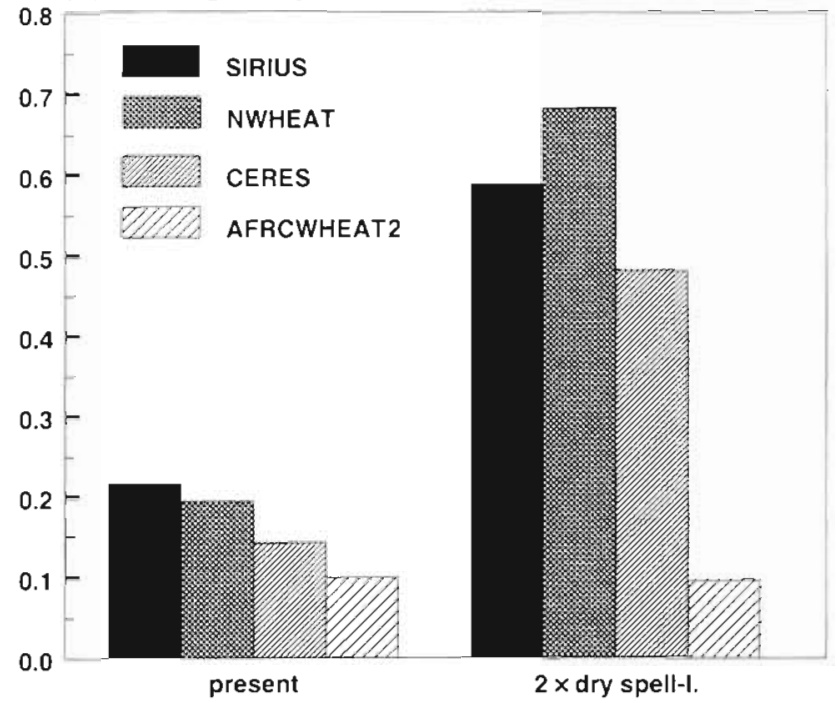

Fig. 10. Sensitivity of (a) grain yield and (b) CV of grain yield to rainfall distribution for winter wheat in Seville, Spain, as simulated with the SIRIUS, NWHEAT, CERES and AFRCWHEAT2 models for the water-limited (-I) production situation. Results were established for $30 \mathrm{yr}$ of generated weather data for the baseline climate where the length of dry spells was doubled

\section{SUMMARY AND CONCLUSIONS}

In the calibration analyses, phenology, total biomass and grain yields were simulated reasonably well by the different models for both the Rothamsted and Seville sites. Further comparisons between experimental and simulated data for Seville were not possible.

Harvest index in the Rothamsted experiments changed very little with water shortage and this was only reproduced well by AFRCWHEAT2. The time course of LAI was generally not well simulated by most of the models. Fortunately, dry matter production is hardly affected by LAI values varying between 4 and 10. The time courses of LAI calculated for both sites only differed slightly and were therefore considered to be characteristic for each model.

Cumulative evapo-transpiration for the Rothamsted experiments was simulated quite accurately by the different models. Differences between observed and predicted evapo-transpiration were often caused by the amount of available water in the models, which mainly depended on assumed soil water storage. Nitrogen uptake by the crop was also predicted quite well by the various models, although the simulated time course was not always identical to the observed. Differences in nitrogen uptake were mainly caused by differences in estimated amounts of mineral nitrogen in the rooted soil profile and their availability for crop uptake. These factors generally limited nitrogen uptake at the end of the growth period.

A summary of the sensitivity of grain yield predictions from the 5 wheat models to changes in mean climatic variables, climatic variability and atmospheric
$\mathrm{CO}_{2}$ concentration is given in Table 5. Increasing mean temperature from the baseline conditions resulted in a decrease in grain yield in all model runs for both sites, with little change in the $\mathrm{CV}$ of grain yield. If water supply in the model was severely limiting, a similar effect on yield occurred with decreasing temperature and $\mathrm{CV}$ increased. Cumulative evapo-transpiration predictions varied widely and were dependent on the model applied. For example in the Rothamsted analyses, SIRIUS predicted an increase in evapo-transpiration with increasing temperature, while NWHEAT and CERES predicted a decrease. In addition, the differences in evapo-transpiration among models for Rothamsted were at variance with those for Seville.

Increasing rainfall resulted in an increase in grain yield and cumulative evapo-transpiration, and in a decrease in CV of grain yield. This rainfall effect was found in all model runs for both sites and was stronger if the model water supply was more limiting

Identical increases in grain yield with increasing atmospheric $\mathrm{CO}_{2}$ were predicted by the various models. If increased $\mathrm{CO}_{2}$ concentration led to reduced water limitation, CV of grain yield decreased, otherwise it was essentially unchanged. Cumulative evapotranspiration predictions and their change with increasing $\mathrm{CO}_{2}$ were dependent on the model applied.

With doubled temperature variability, grain yield generally decreased at both sites. Evapo-transpiration was almost the same as in the comparable scenarios with changes in the mean temperature only; however, $\mathrm{CV}$ of grain yield increased. These results illustrate the increased risk of lower yields with increasing tempera- 
Table 5. Summary of the sensitivity of wheat grain yield to changes in mean climate variables, climatic variability and atmospheric $\mathrm{CO}_{2}$ concentration ( $+, 0,-$ : positive, nil, negative effect of increase in temperature, etc., on grain yield; ?: no simulation result). Results are based on simulation runs with the different wheat models for the potential (+I) and water-limited production situations (-I) at Rothamsted, UK, and Seville, Spain

\begin{tabular}{|c|c|c|c|c|c|c|c|c|}
\hline & & \multirow{2}{*}{$\begin{array}{c}\text { AFRCWHEAT2 } \\
-1\end{array}$} & \multicolumn{2}{|c|}{ CERES } & \multicolumn{2}{|c|}{ NWHEAT } & \multirow{2}{*}{$\underset{-1}{\text { SIRIUS }}$} & \multirow{2}{*}{$\begin{array}{c}\text { SOILN } \\
+1\end{array}$} \\
\hline & & & +1 & -1 & +1 & -1 & & \\
\hline \multicolumn{9}{|l|}{ Rothamsted } \\
\hline \multirow[t]{5}{*}{ Sensitivity to: } & temperature & $-(+)^{d}$ & - & - & $-(+)^{d}$ & $-(+)^{d}$ & - & - \\
\hline & precipitation & + & 0 & + & 0 & + & + & 0 \\
\hline & atmospheric $\mathrm{CO}_{2}$ & + & + & + & + & + & + & + \\
\hline & doubled variability in temperature & 0 & - & - & - & - & 0 & - \\
\hline & doubled length of dry spells & 0 & 0 & 0 & 0 & 0 & 0 & 0 \\
\hline \multicolumn{9}{|l|}{ Seville } \\
\hline \multirow[t]{5}{*}{ Sensitivity to: } & temperature & - & - & $-(+)^{a}$ & - & $-(+)^{d}$ & $-(+)^{a}$ & $?$ \\
\hline & precipitation & 0 & 0 & + & 0 & + & + & ? \\
\hline & atmospheric $\mathrm{CO}_{2}$ & + & + & + & + & + & + & $?$ \\
\hline & doubled variability in temperature & - & - & - & - & - & 0 & ? \\
\hline & doubled length of dry spells & 0 & 0 & - & 0 & - & - & $?$ \\
\hline
\end{tabular}

ture variability, due to an increase in the number of days at sub-optimal temperatures and therefore reduced $\mathrm{CO}_{2}$ assimilation. Doubling the length of dry spells generally resulted in smaller values for grain yield and evapo-transpiration and higher values for $\mathrm{CV}$ of grain yield. This effect was more marked at Seville. However, this was mainly caused by the decrease in total rainfall (cumulative rainfall was approximately halved) and only to a limited extent by the change in rainfall distribution.

The main conclusions from this study are:

(1) The observed time courses of crop growth, evapotranspiration and nitrogen uptake in Rothamsted were reproduced reasonably well by the different models, except for LAI.

(2) Difference between model predictions or between model prediction and observed value (e.g. for evapo-transpiration or nitrogen uptake) was often caused by the estimated input data, such as available amount of soil water or soil mineral nitrogen.

(3) The various models calculated almost the same grain yield sensitivity to changes in climatic variables and atmospheric $\mathrm{CO}_{2}$ concentration.

(4) In the sensitivity analyses the various models calculated considerably different values for cumulative evapo-transpiration. This difference can perhaps be explained by the different calculation methods employed

(5) Increased variability of weather variables resulted in lower yields with increased yield variability in most model runs.

(6) Reliability of crop model results can be improved by site calibration and depends on the quality of input data.
Acknowledgements. Many thanks are due to E. M. Barrow (Climatic Research Unit, Univ. of East Anglia) for providing the baseline and sensitivity climate data sets, and to IACRRothamsted (Harpenden, Herts, UK) for providing data from the Brimstone 1985/86 and Stackyard 1984/85 winter wheat experiments. Many thanks are also due to Prof. Dr J. R. Porter (Royal Veterinary and Agricultural Unıversity, Denmark) for his help with the AFRCWHEAT2 model and valuable comments on the paper and Dr P. D. Jamieson (Crop \& Food Research, New Zealand) for his assistance with the SIRIUS model. This work was funded by the Commission of the European Communities' Environment Programme (Contract EV5V-CT93-0294). IACR received grant-aided support from the Biotechnology and Biological Science Research Council of the UK

\section{LITERATURE CITED}

Barraclough PB, Kuhlmann $\mathrm{H}$, Weir AH (1989) The effects of prolonged drought and nitrogen fertilizer on root and shoot growth and water uptake by winter wheat. J Agron Crop Sci 163:352-360

Barrow EM, Semenov MA. (1995) Climate change scenarios with high temporal and spatial resolution for agricultural applications. Forestry 68:349-360

Eckersten H, Jansson PE (1991) Modelling water flow, nitrogen uptake and production for wheat. Fertilis Res 27 313-329

Eckersten H, Jansson PE, Johnsson H (1994) SOILN model version 8.0. User's manual. Communications 94,4. Section of Hydrotechnics, Department of Soil Sciences, Swedish University of Agricultural Sciences, Uppsala

GCTE (1994) Global Change and Terrestrial Ecosystems Focus 3 Wheat network, Model and experimental meta data. GCTE Core Project Office, Canberra

Godwin D, Ritchie J, Singh U, Hunt L (1990) A user's guide to CERES-Wheat - V2.10. International Fertilizer Development Center, Simulation Manual IFDC-SM-2, Muscle Shoals, AL

Goudriaan J (1996) Predicting crop yields under global 
change. In: Walker DH, Steffen WL (eds) Global change and terrestrial ecosystems. Cambridge University Press, Cambridge

Groot JJR (1987) Simulation of nitrogen balance in a system of winter wheat and soil. Simulation reports CABO-TT no. 13. Centre for Agrobiological Research and Dept of Theoretical Production Ecology, Agricultural University, Wageningen

Groot JJR (1993) NWHEAT; nitrogen balance in a system of winter wheat and soil. In: Engel T, Klöcking B, Priesack E, Schaaf T (eds) Simulationsmodelle zur Stickstoffdynamik, Analyse und Vergleich. Agrarinformatik, Band 25, Ulmer, Stuttgart, p 397-411

Jamieson PD (1989) Modelling the interaction of wheat production and the weather. In: Johnson RWM (ed) Integrated systems analysis and climate impacts. Proceedings of a workshop on systems analysis, Wellington, November 1989. Rural Policy Unit, MAF-Technology, Wellington, p $133-140$

Jamieson PD, Wilson DR (1988) Agronomic uses of a model of wheat growth, development and water use. Proc Agron Soc NZ 18:7-10

Johnsson H, Bergström L, Jansson PE, Paustrian K (1987) Simulation of nitrogen dynamics and losses in a layered agricultural soil. Agric Ecosys Environ 18:333-356

Mearns LO, Schneider SH, Thompson SL, McDaniel LR (1990) Analysis of climate variability in general-circulation models-comparison with observation and changes in variability in $2 \times \mathrm{CO}_{2}$ experiments. J Geophys Res 95: 20469-20490

Porter JR (1984) A model of canopy development in winter wheat. J Agric Sci Cambr 102: 383-392

Porter JR (1993) AFRCWHEAT2: a model of the growth and development of wheat incorporating responses to water and nitrogen. Eur J Agron 2: 69-82

Porter JR, Jamieson PD, Wilson DR (1993) Comparison of the wheat simulation models AFRCWHEAT2, CERES-Wheat

Editor: G. Esser, Gießen, Germany and SWHEAT for non-limiting conditions of crop growth Field Crops Res 33:131-157

Racsko P, Szeidl L, Semenov MA (1991) A serial approach to local stochastic weather models. Ecol Model 57:27-41

RAEA (1989) Variedades de trigos campaña 88/89. Red Andaluza de experimentacion Agraria. Junta de Andalucia, Consejeria de agricultura y pesca, Direccion general de investıgacion y extension agrarias, Seville

RAEA (1991) Variedades de trigos campaña 90/91 Red Andaluza de experimentacion Agraria. Junta de Andailucia, Consejeria de agricultura y pesca, Direccion general de investigacion y extension agrarias, Seville

Rind D, Goldberg R, Ruedy R (1989) Change in climate variability in the 21 st century. Clim Change 14:5-37

Ritchie J, Otter S (1985) Description of and performance of CERES-Wheat: a user-oriented wheat yield model. In: Willis WO (ed) ARS wheat yield project. Department of Agriculture, Agricultural Research Service, ARS-38, Washington, DC, p 159-175

Semenov MA, Porter JR (1995) Climatic variability and the modelling of crop yields. J Agric Forest Met 73:265-283

Semenov MA, Wolf J, Evans LG. Eckersten H, Iglesias A (1996) Comparison of wheat simulation models under climate change. II Application of climate change scenarios. Clim Res 7:271-281

Weir AH (1988) Estimating losses in the yield of winter wheat as a result of drought, in England and Wales. Soil Use Manag 4:33-40

Weir AH, Bragg PL, Porter JR, Rayner JH (1984) A winter wheat crop simulation model without water or nutrient limitations. J Agric Sci Cambr 102:371-382

Wolf J, Semenov MA, Evans LG, Eckersten H, Iglesias A, Porter JR (1995) Effects on winter wheat: a comparison of five models. In: Harrison PA, Butterfield RE, Downing TE (eds) Climate change and agriculture in Europe: assessment of impacts and adaptations. Research Report no. 9, Environmental Change Unit, Oxford, p 231-280

Manuscript first received: February 28, 1996

Revised version accepted: July 9, 1996 